\title{
The metabolic profile of Bifidobacterium dentium reflects its status as a human gut commensal
}

\author{
Melinda A. Engevik ${ }^{1,2,3^{*}}$, Heather A. Danhof ${ }^{4}$, Anne Hall ${ }^{1,2}$, Kristen A. Engevik4 ${ }^{4}$, Thomas D. Horvath ${ }^{1,2}$, \\ Sigmund J. Haidacher ${ }^{1,2}$, Kathleen M. Hoch ${ }^{1,2}$, Bradley T. Endres ${ }^{5}$, Meghna Bajaj ${ }^{6}$, Kevin W. Garey ${ }^{5}$, \\ Robert A. Britton ${ }^{4}$, Jennifer K. Spinler ${ }^{1,2}$, Anthony M. Haag ${ }^{1,2}$ and James Versalovic ${ }^{1,2}$
}

\begin{abstract}
Background: Bifidobacteria are commensal microbes of the mammalian gastrointestinal tract. In this study, we aimed to identify the intestinal colonization mechanisms and key metabolic pathways implemented by Bifidobacterium dentium.

Results: $B$. dentium displayed acid resistance, with high viability over a pH range from 4 to 7 ; findings that correlated to the expression of $\mathrm{Na}+/ \mathrm{H}+$ antiporters within the $B$. dentium genome. $B$. dentium was found to adhere to human MUC2+ mucus and harbor mucin-binding proteins. Using microbial phenotyping microarrays and fullydefined media, we demonstrated that in the absence of glucose, B. dentium could metabolize a variety of nutrient sources. Many of these nutrient sources were plant-based, suggesting that $B$. dentium can consume dietary substances. In contrast to other bifidobacteria, $B$. dentium was largely unable to grow on compounds found in human mucus; a finding that was supported by its glycosyl hydrolase $(\mathrm{GH})$ profile. Of the proteins identified in $B$. dentium by proteomic analysis, a large cohort of proteins were associated with diverse metabolic pathways, indicating metabolic plasticity which supports colonization of the dynamic gastrointestinal environment.
\end{abstract}

Conclusions: Taken together, we conclude that B. dentium is well adapted for commensalism in the gastrointestinal tract.

Keywords: Bifidobacteria, Metabolism, Carbohydrates, Glycans, Acid stress, Intestine, Commensal

\section{Introduction}

Bifidobacteria are important members of the Actinobacteria phylum within the human intestinal microbiota [1-10]. The establishment of bifidobacteria in the intestine is connected with beneficial health effects, including immune development, neuromodulation, inhibition of pathogens, and modulation of the intestinal microbiota composition [11-23]. To produce these beneficial effects, bifidobacteria must be able to survive gastrointestinal (GI) transit and

\footnotetext{
* Correspondence: engevik@musc.edu

'Department of Pathology and Immunology, Baylor College of Medicine, Houston, TX, USA

${ }^{2}$ Department of Pathology, Texas Children's Hospital, Houston, TX, USA

Full list of author information is available at the end of the article
}

persist in the dynamic environment of the intestine. Thus, analysis of the mechanisms of intestinal survival and colonization are pivotal to understand the functional activities of bifidobacteria.

Nutrient availability and utilization shapes the composition and gene expression of the intestinal microbiota [11, 24-30]. Broad genomic approaches have predicted that bifidobacteria can use a wide variety of nutrient sources to colonize the human GI tract [5, 25, 31-35]. More direct studies that have examined growth parameters of bifidobacteria have largely focused on carbohydrate metabolism [36]. As a result, information about the physiology and metabolic profiles of any one Bifidobacterium 
species is fragmented. Identifying the strategies used by specific bifidobacteria to harvest dietary nutrients is important for defining the metabolic properties that underpin ecological fitness in and adaptation to the human intestinal environment. Moreover, this information could be employed to increase the presence of select bifidobacteria in the intestine and harness their associated health benefits.

The aim of this study was to identify key pathways in ecological niche development of Bifidobacterium dentium. B. dentium is a member of the oral and intestinal microbiome. It is frequently isolated from healthy infant stool $[3,6-8]$ and has an approximate relative abundance of $0.7 \%$ in healthy human adults according to the Human Microbiome Project consortium [37-41]. We have previously demonstrated that $B$. dentium colonizes gnotobiotic mice, promotes goblet cell maturation, secretion of the mucin protein MUC2, stimulates intestinal serotonin production, generates the neurotransmitter $\gamma$-aminobutyric acid (GABA), alleviates visceral hypersensitivity and regulates the gut-brain-axis [21-23, $38,42]$. The importance of these functions in GI health motivated us to characterize the metabolic profile of $B$. dentium to identify environmental queues that can influence intestinal colonization.

We sought to characterize the metabolic capacity of $B$. dentium using microbial phenotype microarray technology, genome analysis and proteomics. This work is among the first to delineate the metabolic profile of $B$. dentium ATCC 27678. Our data suggest that $B$. dentium adheres to the intestinal mucus layer, exhibits acid resistance, and utilizes a wide range of physiologically abundant dietary nutrient sources commonly found in the intestine. These data suggest that $B$. dentium is welladapted for life in the gastrointestinal tract.

\section{Methods}

\section{Bacterial culture conditions}

Bifidobacterium dentium ATCC 27678 (ATCC, American Type Culture Collection) was grown in de Man, Rogosa and Sharpe (MRS) medium (Difco) in an anaerobic workstation (Anaerobe Systems AS-580) at $37^{\circ} \mathrm{C}$ overnight in a mixture of $5 \% \mathrm{CO}_{2}, 5 \% \mathrm{H}_{2}$, and $90 \% \mathrm{~N}_{2}$. Bacterial growth was measured by optical density $\left(\mathrm{OD}_{600 \mathrm{~nm}}\right)$ using a spectrophotometer. For intestinal adhesion assays, $B$. dentium was grown overnight in MRS anaerobically at $37^{\circ} \mathrm{C}$ and bacterial cells were pelleted by centrifugation at $5000 \times g$ for 5 min. Cell pellets were washed three times with sterile anaerobic PBS to remove residual MRS and the bacterial pellet was resuspended in anaerobic PBS containing $10 \mu \mathrm{M}$ carboxyfluorescein diacetate succinimidyl ester (CFDA-SE; Thermo Fisher Scientific, Waltham, MA; \#V12883) and incubated for $1 \mathrm{~h}$ anaerobically at $37^{\circ} \mathrm{C}$. Following incubation, bacterial cells were pelleted by centrifugation at $5000 \times g$ for $5 \mathrm{~min}$, and were washed $3-5 \mathrm{x}$ with sterile anaerobic PBS. B. dentium fluorescence was confirmed by microscopy and were used for adhesion with the HT29-MTX mammalian cell cultures.

For an acid stress test, $B$. dentium was grown in MRS anaerobically at $37^{\circ} \mathrm{C}$ for $8 \mathrm{~h}$ to exponential phase and bacterial cells were pelleted by centrifugation at $5000 \times g$ for 5 min. $B$. dentium was resuspended at an $\mathrm{OD}_{600 \mathrm{~nm}}=$ 2.0 in MRS at a pH of 7.6, 7.0, 6.0, 5.0, 4.0, and 3.0 to simulate the different regions of the GI tract. $B$. dentium was incubated anaerobically at $37^{\circ} \mathrm{C}$ for $2 \mathrm{~h}$ in the various $\mathrm{pH}$ conditions. Following incubation, $B$. dentium cells were pelleted by centrifugation at $5000 \times \mathrm{x} g$ for 5 min, washed $2 x$ to remove residual MRS and then resuspended in anaerobic PBS. Cells were stained with the LIVE/DEAD BacLight Bacterial Viability Stains (Thermo Fisher Scientific cat\# L7012) according to the manufacturer's details. Briefly, $B$. dentium was mixed with a $2 x$ LIVE/DEAD BacLight staining reagent mixture and incubated for $15 \mathrm{~min}$ in the dark at $37^{\circ} \mathrm{C}$ anaerobically. Then a $100 \mu \mathrm{L}$ volume of each of the $B$. dentium cell suspensions were added to a black-walled 96-well flatbottom microplate. Fluorescence was recorded using the following excitation (ex) and emission (em) wavelengths: ex: $485 \mathrm{~nm} / \mathrm{em}$ : $530 \mathrm{~nm}$ (green) and ex: $485 \mathrm{~nm} / \mathrm{em}: 630$ $\mathrm{nm}$ (red) on a Synergy H1 Microplate Reader (Bio-Tek Instruments, Inc.). Viabilities were calculated with the following equation: (ex: 485/em: 530 values)/(ex:458/em: 630 values $) \times 100 \%$ (Ratio green $/$ red $\times 100 \%)$.

\section{Intracellular $\mathrm{pH}$ assay}

$B$. dentium was grown in MRS for $24 \mathrm{~h}$ from a starter culture inoculated at $\mathrm{OD}_{600 \mathrm{~nm}}=0.1$. From this starter culture, a $100 \mu \mathrm{L}$ volume of bacterial suspension was transferred to a conical bottomed 96-well plate and pelleted by centrifugation at $2000 \times g$ for $5 \mathrm{~min}$. Cell pellets were washed twice in live cell imaging solution (LCIS, Molecular Probes) and then resuspended in LCIS containing 1x pHrodo Red AM dye (provided as 1000x in dimethyl sulfoxide, DMSO) and 1x PowerLoad (provided as 100x) (Molecular Probes). B. dentium was incubated anaerobically at $37^{\circ} \mathrm{C}$ for $30 \mathrm{~min}$. Following incubation, bacterial cells were pelleted by centrifugation at $2000 \mathrm{x} g$ for $5 \mathrm{~min}$ to remove excess staining solution and then were resuspended in a $100 \mu \mathrm{L}$ volume of LCIS. Using a vacuum manifold with $\sim 5$ in $\mathrm{Hg}$ vacuum pressure, $B$. dentium cells were immobilized on a $0.22 \mu \mathrm{m}$-pore polyvinylidene fluoride (PVDF) filter plate (Millipore Sigma, Burlington, MA). Filters were washed once by vacuum and wells were refilled with LCIS. The filter plate was then loaded into a Synergy HT plate reader with incubation at $37^{\circ} \mathrm{C}$. A citrate buffer series was used to examine intracellular $\mathrm{pH}$ due to the wide $\mathrm{pH}$ range and its successful application with other lactic acid bacteria [43]. 
Fluorescence (ex: $560 \mathrm{~nm} / \mathrm{em}$ : $590 \mathrm{~nm}$ ) was recorded every $5 \mathrm{~min}$ over a $50 \mathrm{~min}$ timeframe, first in a common buffer ( $\mathrm{pH} 7.6, \mathrm{~min} 0-10)$, then in the test buffers at $\mathrm{pH}$ 3-8 (min 10-50). Higher relative fluorescence unit (RFU) values indicate more acidic conditions. Standard curves were generated from fluorescence readings taken over $10 \mathrm{~min}$ in potassium citrate buffers at $\mathrm{pH} 4.5,5.5$, 6.5 , and 7.5 in the presence of $10 \mu \mathrm{M}$ valinomycin and $10 \mu \mathrm{M}$ nigericin to equilibrate intra- and extracellular $\mathrm{pH}$. Intracellular $\mathrm{pH}$ was calculated at the final test buffer time point $(t=50 \mathrm{~min})$ from linear regression lines.

\section{Biolog phenotypic microarray}

For Biolog assays, $B$. dentium was grown overnight $(\sim 16 \mathrm{~h})$ in MRS as described above. Cells were then diluted 1:20 in a fully-defined medium, termed LDM4 (Lactic Acid Bacteria Defined Media 4) [44], lacking glucose. Each well of Biolog NPGM2 and PM1 microarrays (Biolog, Inc., Haywood, CA, USA) was seeded with a $100 \mu \mathrm{L}$ volume of cell suspension. Growth was monitored by Optical density $\left(\mathrm{OD}_{600 \mathrm{~nm}}\right)$ readings at $10 \mathrm{~min}$ intervals for $16 \mathrm{~h}$. Growth was assessed compared to a negative control well lacking any carbon substrate and a value of $\mathrm{OD}_{600 \mathrm{~nm}} \geq 0.2$ was considered positive $(n=2$ independent biological replicates per plate).

\section{Bacterial genome analysis}

The genome of B. dentium ATCC 27678 (GCF_00017213 5.1) was downloaded from NCBI and functionally assessed using the web-based tools NCBI Conserved Domain Database, Carbohydrate Active Enzymes (CAZy; www.cazy.org), and KEGG [45-48].

\section{Mammalian culture conditions}

HT29-MTX cells were obtained from Millipore-Sigma (\#12040401). Cells were maintained in Gibco Dulbecco's Modified Eagle Medium (Thermo Fisher Scientific) containing $10 \%$ fetal bovine serum (FBS) in a humidified atmosphere at $37^{\circ} \mathrm{C}, 5 \% \mathrm{CO}_{2}$. Cells were tested for Mycoplasma using the Mycoplasma Detection Kit (Lonza, cat\# LT07-518). For adhesion assays, HT29MTX cells were seeded at $2 \times 10^{5}$ cells on poly-L-lysine coated round coverslips and incubated for 3-5 days until confluent. When monolayers were confluent, HT29MTX cells were incubated with Hoechst 33342 staining dye solution (Invitrogen) in PBS for $10 \mathrm{~min}$ at $37^{\circ} \mathrm{C}$, washed, and treated with $1 \times 10^{7}$ cells of CFDA-tagged B. dentium for $1 \mathrm{~h}$ aerobically at $37^{\circ} \mathrm{C}$. After the incubation, non-adhered cells were removed with $3 \mathrm{x}$ washes of PBS and cells were fixed with Clarke's Fixative to maintain the mucus architecture. A subset of cells were used for Scanning Electron Microscopy (SEM) imaging using a FEI XL-30FEG microscope. Cells that were reserved for immunostaining were permeabilized with $0.1 \%$ Triton-
$\mathrm{X}$ for $30 \mathrm{~min}$ at room temperature, blocked with PBS containing $10 \%$ donkey serum, and incubated with an antihuman MUC2 antibody (Santa Cruz, cat \# sc-515,032; 1 : 200 dilution) overnight at $4{ }^{\circ} \mathrm{C}$. Following PBS washes, cells were incubated with donkey-anti-mouse AlexaFluor 555 (Life Technologies, cat \# A11004; 1:1000 dilution) for $1 \mathrm{~h}$ at room temperature. Coverslips were mounted to slides using FluoroMount (Thermo Fisher Scientific) and slides were imaged on the Nikon Eclipse TiE inverted microscope.

\section{Scanning electron microscopy (SEM)}

Following imaging, the wells of the slides were washed gently with PBS containing $\mathrm{Mg}^{2+}$ and $\mathrm{Ca}^{2+}(2 \mathrm{x})$ and fixed in $2.5 \%$ glutaraldehyde in PBS for $1 \mathrm{~h}$ at room temperature as previously described [42]. The black compartment of the CELLview slide was detached, the slide was dehydrated with ethanol, and coated in $20 \mathrm{~nm}$ of gold using a desktop sputtering system (Denton Desk II). All slides were viewed in a FEI XL-30FEG SEM microscope operated with an electron beam acceleration voltage of $12 \mathrm{kV}$ [42].

\section{Proteomic analysis \\ Chemical and reagents}

Optima LC/MS-grade acetonitrile (ACN), formic acid (FA), and water, and Promega ${ }^{\mathrm{Th}}$ porcine trypsin protease were all purchased from Thermo Fisher Scientific. Ammonium bicarbonate (BioUltra-grade) was purchased from Millipore-Sigma.

\section{Proteomics sample preparation}

Bacterial sample pellets were suspended in a $200-\mu \mathrm{L}$ volume of water and samples were sonicated in an ultrasonic bath for $30 \mathrm{~min}$. Afterwards, the samples were centrifuged for $5 \mathrm{~min}$ at $10,000 \mathrm{rpm}$. The resulting sample supernatants containing bacterial protein were removed from the pellet of cellular debris, and the samples were dried in a SpeedVac overnight to yield pelleted protein in the sample tubes. A $100-\mu \mathrm{L}$ volume of a $10 \mu \mathrm{g} / \mathrm{mL}$ solution of porcine trypsin prepared in a $25 \mathrm{mM}$ ammonium bicarbonate solution was added to the pelleted protein contained in each sample tube, and the samples were vortex-mixed for $1 \mathrm{~min}$ and incubated at $37^{\circ} \mathrm{C}$ for $8 \mathrm{~h}$.

\section{Chromatography}

Tryptic digest samples were chromatographically separated on a Dionex Ultimate 3000 RSLC nano-system (Thermo Scientific) using an Acclaim PepmapTM C-18 capillary column $(75 \mu \mathrm{m}$ (ID) $\times 150 \mathrm{~mm}$ (L), Thermo Scientific) outfitted with an Acclaim PepmapTM C18 trap column $(100 \mu \mathrm{m}$ (ID) $\times 20 \mathrm{~mm}(\mathrm{~L})$, Thermo Scientific). Chromatography was performed as previously described [22]. Elution gradients were prepared from an aqueous 
mobile phase (A) of H2O:ACN:FA (94.9:5:0.1 v/v/v) and an organic mobile phase (B) of ACN:FA (99.9:0.1 v/v). Sample elution onto the trap column was carried out using a trap column buffer of H2O:ACN:FA (94.9:5:0.1 $v / v / v)$. Samples $(5 \mu \mathrm{L})$ were injected onto the trap column with a flow rate of $5 \mu \mathrm{L} / \mathrm{min}$. After $5 \mathrm{~min}$, the loading valve was switched to allow the sample to elute off the trap column at a flow rate of $300 \mathrm{~nL} / \mathrm{min}$ and onto the capillary column for separation. The elution gradient used was specified as follows: Started at $1 \%$ B, ramped up linearly to $45 \%$ B over 37 min; ramped up linearly to $80 \%$ B over 1 min; held at $80 \%$ B for $1 \mathrm{~min}$; ramped back to $1 \% \mathrm{~B}$ over $1 \mathrm{~min}$ and held for 16 min to re-equilibrate.

\section{Mass spectrometric conditions}

Samples were analyzed using an Orbitrap Fusion mass spectrometer (Thermo Scientific) using a nanoionization source operated in positive ion mode with the following source conditions: ionspray voltage, static at $1.6 \mathrm{kV}$; ion transfer tube temperature, $275^{\circ} \mathrm{C}$. Global MS acquisition parameters were specified as follows: precursor ion scan range, mass-to-charge $(\mathrm{m} / z) 200-\mathrm{m} / z$ 1000; S-lens RF level, 60\%; data type, profile; MIPS, true; charge states, 2-4; data dependent mode, top speed; precursor priority, most intense; exclude after $\mathrm{n}$ times, 1 : exclusion duration, 60s; mass tolerance, parts-per-million (ppm); low/high, 10; exclude isotopes, true; MSn level, 2; isolation mode, quadrupole; isolation window, $\mathrm{m} / z$ 1.6; CID activation, true; CID collision energy, 35\%; detector type, Orbitrap; scanrange mode, auto; orbitrap resolution, 120,000; automatic gain control (AGC) target, 5.0e4; maximum injection time, $60 \mathrm{~ms}$; microscans, 1; and, tandem MS data format, profile. Data were acquired with the Thermo Scientific Xcalibur software package (v4.1.50).

\section{Mass spectrometric data analysis}

Data were analyzed using Proteome Discoverer (Thermo Scientific). Data were searched against the Uniprot Bifidobacterium database (8 Aug 2020) which also included a common contaminant database. The following parameters were used for protein identification: minimum precursor mass, 350 Dalton (Da); maximum precursor mass, $5000 \mathrm{Da}$; minimum peak count, 1; minimum peptide length, 6; precursor mass tolerance, $10 \mathrm{ppm}$; fragment mass tolerance, $0.02 \mathrm{Da}$; dynamic modifications included oxidation for methionine and acetylation for protein $\mathrm{N}$ terminus; target and decoy database, concatenated; validation based on q-Value; and, FDR targets were 0.01 for strict and 0.05 for relaxed.

\section{Statistics and graphs}

Graphs and heat maps were created using GraphPad Prism software (version 8) (GraphPad Inc.). Comparisons were made with either One-way ANOVA or Repeated
Measures ANOVA with the Holm-Sidak post-hoc test. The data are presented as mean \pm standard deviation, with

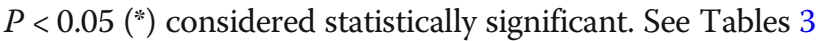
and 4 and Supplemental Table 1 and Supplemental Table 2 for statistical analysis.

\section{Results}

\section{B. dentium is acid resistant and can adhere to intestinal mucus suggesting its efficacy to persist in the gastrointestinal tract}

To colonize the gastrointestinal tract microbes must overcome the acidic $\mathrm{pH}$ found in the stomach and upper GI to gain access to the lower parts of the intestine. In general, bifidobacteria are considered to have a weak acid tolerance with the exception of B. animalis [49] and B. longum [50-52]. Using the NCBI Conserved Domain Database to assess the functional annotation of the $B$. dentium ATCC 27678 (GCF_000172135.1) proteins, we noted the presence of three $\mathrm{Na}^{+} / \mathrm{H}^{+}$antiporter proteins that may contribute to acid tolerance in $B$. dentium [45-48] (Table 1). To address the ability of $B$. dentium to survive transit through the low $\mathrm{pH}$ environment of the stomach and small intestine experimentally, we incubated overnight cultures of $B$. dentium in MRS with $\mathrm{pH}$ of 3, 4, 5, 6, and 7 for $2 \mathrm{~h}$. After incubation, cell viability was obtained by live/dead cell staining using a BACLight kit as examined by microscopy (Fig. 1a) and fluorescence plate reader quantification (Fig. 1b). B. dentium exhibited high viability over a $\mathrm{pH}$ range from 4 to 7 , as denoted by green staining, and $>90 \%$ viability levels. Even in highly acidic conditions ( $\mathrm{pH} 3), B$. dentium still maintained $41.8 \% \pm 2.4$ viability, indicating acid tolerance. Intracellular $\mathrm{pH}$ analysis by pHrodo Red AM dye demonstrated that surviving $B$. dentium were able to regulate their intracellular $\mathrm{pH}$ over time (Fig. $1 \mathrm{c}, \mathrm{d})$. These data suggest that $B$. dentium is acidtolerant, similar to findings with gastrointestinal colonizers $B$. animalis and B. longum [53], and thus likely able to survive the transit through the upper GI system.

The ability to adhere to the intestinal mucus layer is an important aspect of bifidobacterial colonization [54]. Mucus adhesion is proposed to enhance epithelial integrity and pathogen exclusion [55], as well as provide closer access for metabolite delivery and immune

Table 1 Notable ion antiporters identified from the genome of Bifidobacterium dentium ATCC 27678

\begin{tabular}{lll}
\hline Accession No. & Description & Proposed Function \\
\hline WP_003840740.1 & $\mathrm{Na}^{+} / \mathrm{H}^{+}$antiporter & Acid tolerance \\
WP_003837813.1 & cation:proton antiporter & Acid tolerance \\
WP_003838459.1 & $\mathrm{Na}^{+} / \mathrm{H}^{+}$antiporter & Acid tolerance \\
\hline
\end{tabular}



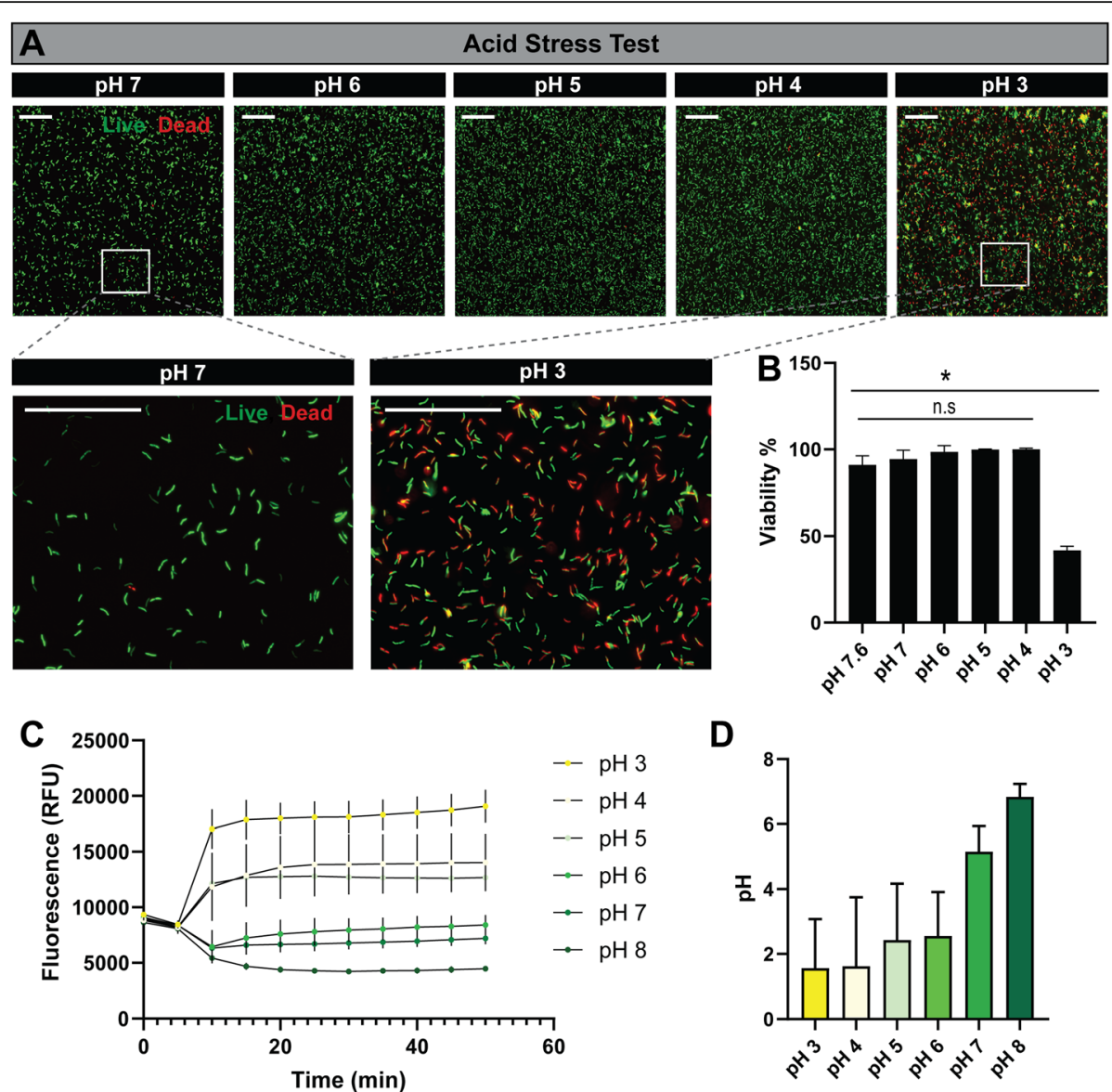

D

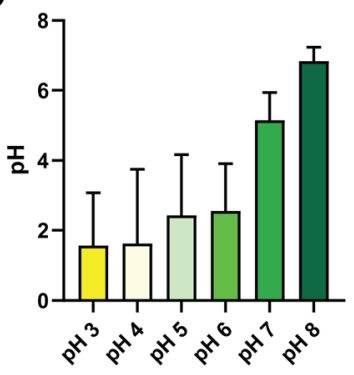

Fig. 1 Bifidobacterium dentium is resistant to acid stress. a Representative images of live/dead staining of $B$. dentium ATCC 27678 after $2 \mathrm{~h}$ incubation in media at $\mathrm{pH} 7,6,5,4$, and 3. Inserts at high magnification highlight the abundance of live (green) and dead (red) $B$. dentium at pH 7 and $\mathrm{pH} 3$ (scale bar $=50 \mu \mathrm{m}$ ). b Quantitation of live/dead cell staining on a fluorescent plate reader. $\mathbf{c}$ Intracellular pH analysis of $B$. dentium with pHrodo Red pH sensitive dye. Variance in intracellular pH is reflected by the change in relative fluorescence units (RFU), at various extracellular pH values over $50 \mathrm{~min}$. $\mathbf{d}$ Calculated final intracellular $\mathrm{pH}$ values at $\mathrm{t}=50 \mathrm{~min}$. All data are presented as mean $\pm \mathrm{stdev}$

stimulation [56, 57]. Investigation of the functional annotation of $B$. dentium ATCC 27678 indicated the presence of glycosyltransferase enzymes that promote bacterial capsular formation along with pilin and fimbrial proteins (Table 2). These proteins have been previously associated with mucus adherence and GI colonization and may also facilitate mucus adhesion for $B$. dentium. To assess adhesion of $B$. dentium to intestinal mucus, we added fluorescently-tagged $B$. dentium to human mucin-producing HT29-MTX monolayers for $1 \mathrm{~h}$ and examined adhesion by immunostaining (Fig. 2). Similar to other well characterized Bifidobacterium strains, we observed robust adhesion of $B$. dentium to MUC2 mucin by immunostaining (Fig. 2a) and SEM imaging (Fig. 2b). The ability of $B$. dentium to withstand acidic conditions and adhere to intestinal mucus highlights its potential to inhabit the intestine.

\section{B. dentium metabolism of dietary sugars and select host derived carbon sources promote growth}

Previous work examining microbe metabolism have relied on adding nutritional components to rich media, such as MRS. However, the complexity of this medium, poses challenges to identification of the dietary requirements of these microbes. To circumvent this challenge we used LDM4 media, a fully-defined medium which can be prepared to exact nutrient composition [44]. Using LDM4 prepared without glucose, we examined the ability of $B$. dentium to grow on a number of nutrients as individual primary carbon sources by Biolog phenotype analysis (Fig. 3, Tables 3 and 4). Growth of $B$. dentium was examined in the presence of 50 different sugars, including hexoses (Fig. 3a), pentoses (b), ketoses (c), disaccharides (d), trisaccharides (e), sugar alcohols (f), deoxy sugars (g) and amino sugars (h). As shown in 
Table 2 Notable glycosyltransferases and proteins involved in adhesion identified from the genome of Bifidobacterium dentium ATCC 27678

\begin{tabular}{lll}
\hline Accession No. & Description & Proposed Function \\
\hline WP_003837192.1 & Glycosyltransferase family 2 & Bacterial capsule biosynthesis \\
WP_003837196.1 & Glycosyltransferase family 2 & Bacterial capsule biosynthesis \\
WP_003836797.1 & Glycosyltransferase family 2 & Bacterial capsule biosynthesis \\
WP_003836799.1 & Glycosyltransferase family 1 & Exopolysaccharide biosynthesis \\
WP_003837542.1 & Glycosyltransferase family A & mannose-1-phosphate guanylyltransferase \\
WP_003837819.1 & Glycosyltransferase family 2 & Bacterial capsule biosynthesis \\
WP_003838069.1 & Glycosyltransferase family B & GT transferase \\
WP_034257238.1 & Glycosyltransferase family 4 protein & Cell wall biosynthesis \\
WP_033488900.1 & Glycosyltransferase & Anthranilate phosphoribosyltransferase \\
WP_034257219.1 & Nucleotidyltransferases & 2-C-methyl-D-erythritol 4-phosphate cytidylyltransferase \\
WP_003837207.1 & Isopeptide-forming fimbrial protein & Pilus formation
\end{tabular}

the graphs and heat map (Fig. 3i), B. dentium exhibits robust growth with a variety of carbohydrates, with substantial growth found on galactose, mannose, maltose, xylose, sucrose, truanose, D-raffinose, maltotriose, stachyose, D-melibiose, gentiobiose, sedoheptulosan and D-mannitol. These findings are consistent with the $B$. dentium $\mathrm{Bd} 1$ genome analysis [33], which indicated that $B$. dentium encoded a wide variety of enzymes for the fermentation of pentose sugars. The utilization of sucrose by $B$. dentium ATCC 27678 was reflected by our proteomic analysis, in which we identified 24 proteins involved in sucrose metabolism (Table 5). We also identified proteins involved in maltose-binding (MalE), maltose transport systems (MalG), xylose isomerases, xylose $A B C$ transporters, raffinose-binding, mannose metabolism, and
$\mathrm{ABC}$ sugar transports (Table 5); findings which reflect our growth profiles. No appreciable growth was observed on many sugars, including D- or L-arabitol, lactitol, maltitol, D-lactose, D-cellboiose, D-trehalose, lactulose, fucose, among others. The inability of $B$. dentium ATCC 27678 to use fucose is consistent a previous study that demonstrate that $B$. dentium DSM 20436 and VBif10D2 are unable to use fucose in mYCFA medium [58]. In this capacity, $B$. dentium resembles most Bifidobacterium species which are largely unable to use fucose [58].

The B. dentium ATCC 27678 genome contains 88 glycosyl hydrolase $(\mathrm{GH})$ genes from 25 different $\mathrm{GH}$ families (Fig. 4). The majority of the $B$. dentium ATCC $27678 \mathrm{GH}$ genes are found in families GH3 (14\%), GH13 (14\%), and GH43 (16\%). The GH13 family
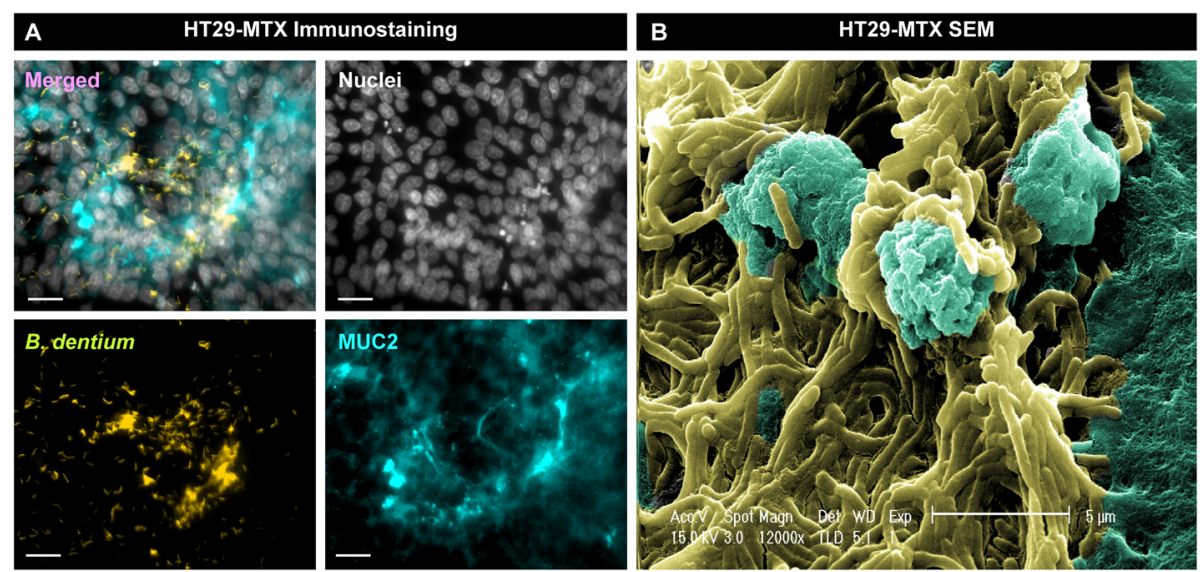

Fig. 2 B. dentium adheres to mucus-producing human intestinal epithelial cells. a Representative immunofluorescence images of $B$. dentium ATCC 27678 (yellow) co-localization with MUC2 (blue) in mucin-producing human HT29-MTX colonic cells after $1 \mathrm{~h}$ incubation (scale bar $=50 \mu \mathrm{m})$. b Scanning electron micrograph of $B$. dentium and HT29-MX cells after $1 \mathrm{~h}$ incubation (scale bar $=5 \mu \mathrm{m}$ ) 


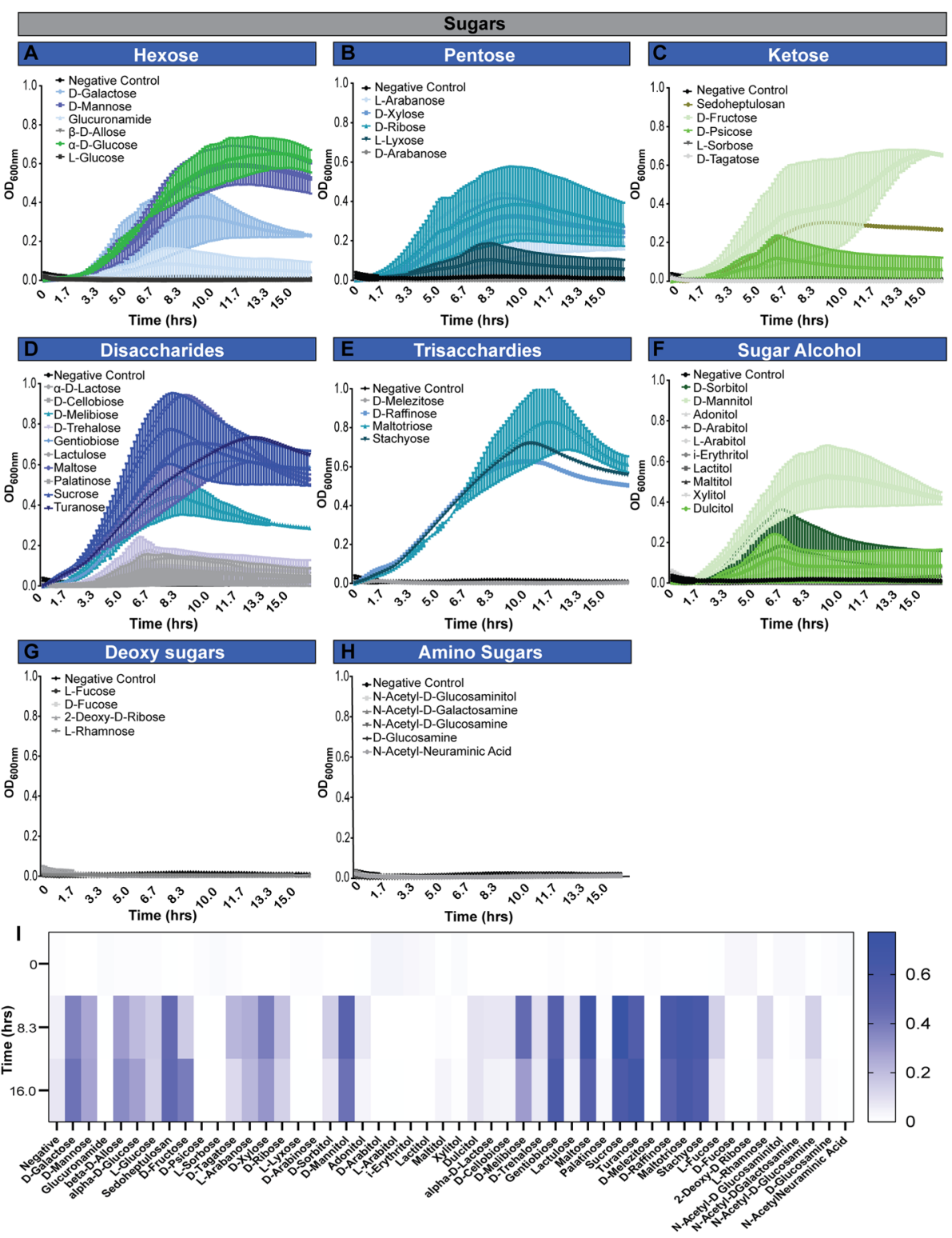

Fig. 3 B. dentium grows on select sugars in the absence of glucose. B. dentium ATCC 27678 was grown anaerobically at $37^{\circ} \mathrm{C}$ in Biolog plates with a fully-defined media (LDM4) preparation that lacked glucose. Growth was monitored over $16 \mathrm{~h}$ by plate reader in plate containing a hexoses, $\mathbf{b}$ pentoses, $\mathbf{c}$ ketoses, $\mathbf{d}$ disaccharides, e trisaccharides, $\mathbf{f}$ sugar alcohols, $\mathbf{g}$ deoxy sugars and $\mathbf{h}$ amino sugars. i For visualization, heat maps were generated for all sugars at time $0,8.3$ and $16.0 \mathrm{~h}$. All data are presented as mean \pm stdev

encodes enzymes which degrade $\alpha$-glucoside linkages, such as $\alpha$-amylases $[59,60]$, while the GH43 family contains xylanase (which break down plant-derived hemicellulose into xylose and arabinose) as well as arabinases (which degrade complex polysaccharides or arabino-oligosaccharides and liberate L-arabinose). The GH3 family notably contains $\beta$-glucosidases, $\beta$-xylosidases, $\mathrm{N}$-acetylhexosaminidase, and other enzymes. The presence of these GHs suggests a high propensity to degrade dietary plant polysaccharides.
Interestingly, we observed few GHs associated with human milk oligosaccharide (HMOs) or mucin degradation. B. dentium did possess genes in GH2 (6.8\%; galactosidase); GH 29 (1.1\%; fucosidase), and GH125 (1.1\%; mannosidase). Surprisingly, B. dentium lacked GH33, GH101, GH129, GH84, GH85, GH89, GH95, GH20, and GH38; which are involved in $\mathrm{HMO}$ and mucin degradation and common in some Bifidobacterium species [42]. Consistent with these findings, the experimental carbohydrate utilization profile (Fig. 3) indicates poor or absent growth 
Table 3 Statistics from growth curves at time point, $8.3 \mathrm{~h}$. Significant $p$ values are denoted as follows: ${ }^{*} P<0.05,{ }^{* *} P<0.01$, ${ }^{* * *} P<0.001$, ${ }^{* * * *} P<0.0001$

\begin{tabular}{|c|c|c|c|}
\hline & $8.3 \mathrm{hrs}$ & & \\
\hline Comparison & $95.00 \% \mathrm{Cl}$ of diff. & Significant? & $P$ Value \\
\hline Negative vs. D-Galactose & -0.7584 to -0.09959 & $* *$ & 0.0022 \\
\hline Negative vs. D-Mannose & -0.8634 to -0.2046 & $* * * *$ & $<0.0001$ \\
\hline Negative vs. alpha-D-Glucose & -0.8554 to -0.1966 & $* * * *$ & $<0.0001$ \\
\hline Negative vs. Sedoheptulosan & -0.7294 to -0.07059 & ** & 0.0061 \\
\hline Negative vs. D-Xylose & -0.6594 to -0.0005865 & * & 0.0492 \\
\hline Negative vs. D-Mannitol & -0.7794 to -0.1206 & ** & 0.0011 \\
\hline Negative vs. D-Melibiose & -0.7194 to -0.06059 & $* *$ & 0.0084 \\
\hline Negative vs. Gentiobiose & -0.7994 to -0.1406 & $* * *$ & 0.0005 \\
\hline Negative vs. Maltose & -0.9494 to -0.2906 & $* * * *$ & $<0.0001$ \\
\hline Negative vs. Sucrose & -1.049 to -0.3906 & $* * * *$ & $<0.0001$ \\
\hline Negative vs. Turanose & -0.8294 to -0.1706 & $* * *$ & 0.0002 \\
\hline Negative vs. D-Raffinose & -0.8694 to -0.2106 & $* * * *$ & $<0.0001$ \\
\hline Negative vs. Maltotriose & -0.9094 to -0.2506 & $* * * *$ & $<0.0001$ \\
\hline Negative vs. Stachyose & -0.8794 to -0.2206 & $* * * *$ & $<0.0001$ \\
\hline Negative vs. D-Gluconic Acid & -0.5014 to -0.03863 & $* *$ & 0.0097 \\
\hline Negative vs. L-Proline & -0.7237 to -0.03635 & * & 0.0206 \\
\hline Negative vs. Sec-Butylamine & 0.004907 to 0.03509 & * & 0.013 \\
\hline Negative vs. Amygdalin & -0.4010 to -0.09401 & $* * * *$ & $<0.0001$ \\
\hline Negative vs. Arbutin & -0.3325 to -0.02551 & * & 0.0107 \\
\hline Negative vs. Salicin & -0.3335 to -0.02651 & * & 0.01 \\
\hline & $16 \mathrm{hrs}$ & & \\
\hline Comparison & $95.00 \% \mathrm{Cl}$ of diff. & Significant? & $P$ Value \\
\hline Negative vs. D-Mannose & -0.8481 to -0.2299 & $* * * *$ & $<0.0001$ \\
\hline Negative vs. alpha-D-Glucose & -0.9221 to -0.3039 & $* * * *$ & $<0.0001$ \\
\hline Negative vs. Sedoheptulosan & -0.6891 to -0.07092 & $* *$ & 0.0052 \\
\hline Negative vs. D-Mannitol & -0.6491 to -0.03092 & * & 0.0198 \\
\hline Negative vs. Gentiobiose & -0.8191 to -0.2009 & $* * * *$ & $<0.0001$ \\
\hline Negative vs. Maltose & -0.7591 to -0.1409 & $* * *$ & 0.0004 \\
\hline Negative vs. Sucrose & -0.8091 to -0.1909 & $* * * *$ & $<0.0001$ \\
\hline Negative vs. Turanose & -0.8791 to -0.2609 & $* * * *$ & $<0.0001$ \\
\hline Negative vs. D-Raffinose & -0.7291 to -0.1109 & $* *$ & 0.0012 \\
\hline Negative vs. Maltotriose & -0.8391 to -0.2209 & $* * * *$ & $<0.0001$ \\
\hline Negative vs. Stachyose & -0.7891 to -0.1709 & $* * *$ & 0.0001 \\
\hline Negative vs. D-Gluconic Acid & -0.3574 to -0.08257 & $* * * *$ & $<0.0001$ \\
\hline Negative vs. Amygdalin & -0.6605 to -0.4385 & $* * * *$ & $<0.0001$ \\
\hline Negative vs. Inosine & -0.2255 to -0.003522 & * & 0.038 \\
\hline Negative vs. Arbutin & -0.4595 to -0.2375 & $* * * *$ & $<0.0001$ \\
\hline Negative vs. Salicin & -0.4375 to -0.2155 & $* * * *$ & $<0.0001$ \\
\hline
\end{tabular}


Table 4 Statistics from growth curves at time point, $16.0 \mathrm{~h}$. Significant $p$ values are denoted as follows: ${ }^{*} P<0.05$, ${ }^{* *} P<0.01$, ${ }^{* * *} P<0.001,{ }^{* * * *} P<0.0001$

\begin{tabular}{|c|c|c|c|}
\hline Comparison & $95.00 \% \mathrm{Cl}$ of diff. & Significant? & $P$ Value \\
\hline Negative vs. D-Mannose & -0.8481 to -0.2299 & **** & $<0.0001$ \\
\hline Negative vs. alpha-D-Glucose & -0.9221 to -0.3039 & $* * * *$ & $<0.0001$ \\
\hline Negative vs. Sedoheptulosan & -0.6891 to -0.07092 & ** & 0.0052 \\
\hline Negative vs. D-Mannitol & -0.6491 to -0.03092 & * & 0.0198 \\
\hline Negative vs. Gentiobiose & -0.8191 to -0.2009 & $* * * *$ & $<0.0001$ \\
\hline Negative vs. Maltose & -0.7591 to -0.1409 & $* * *$ & 0.0004 \\
\hline Negative vs. Sucrose & -0.8091 to -0.1909 & **** & $<0.0001$ \\
\hline Negative vs. Turanose & -0.8791 to -0.2609 & $* * * *$ & $<0.0001$ \\
\hline Negative vs. D-Raffinose & -0.7291 to -0.1109 & $* *$ & 0.0012 \\
\hline Negative vs. Maltotriose & -0.8391 to -0.2209 & $* * * *$ & $<0.0001$ \\
\hline Negative vs. Stachyose & -0.7891 to -0.1709 & *** & 0.0001 \\
\hline Negative vs. D-Gluconic Acid & -0.3574 to -0.08257 & $* * * *$ & $<0.0001$ \\
\hline Negative vs. Amygdalin & -0.6605 to -0.4385 & **** & $<0.0001$ \\
\hline Negative vs. Inosine & -0.2255 to -0.003522 & * & 0.038 \\
\hline Negative vs. beta-Methyl-DXyloside & -0.06148 to 0.1605 & ns & 0.9514 \\
\hline Negative vs. Arbutin & -0.4595 to -0.2375 & $* * * *$ & $<0.0001$ \\
\hline Negative vs. Salicin & -0.4375 to -0.2155 & $* * * *$ & $<0.0001$ \\
\hline
\end{tabular}

on components of host-derived glycans as a sole carbon source, including lactose, N-acetylgalactosamine, Nacetylglucosamine or $\mathrm{N}$-acetylneuraminic acid that would most likely require GH genes from families GH33, GH95, and GH101 (Fig. 3a, d, g, h and i). Consistent with the presence of GH43 and GH125, host-associated galactose and mannose supported growth of $B$. dentium (Fig. 3a), indicating select host factors influence $B$. dentium colonization and growth. As expected, $B$. dentium growth (i.e., a final $\mathrm{OD}_{600 \mathrm{~nm}}$ of $>0.2$ ) was also observed on certain plant-derived carbohydrates such as maltose, melibiose, sucrose, ribose, fructose, and turanose (Fig. 3i). These data suggest that in the absence of glucose, $B$. dentium is able to support its growth via 14 different sugars, most of which are plant-derived and may have variable availability depending on the host diet.

\section{B. dentium has limited ability to use amino acids, nucleosides and polymers as a sole carbon source}

The ability to metabolize peptides and amino acids is a common feature among gut microbiota [61]. However, amino acids and nucleotides are often studied as nitrogen sources rather than a primary carbon source. Currently, little information is available on the ability of bifidobacteria to use these substrates as both primary carbon and nitrogen sources in the absence of additional carbohydrates. We examined the growth of $B$. dentium during a time course on a panel of 32 amino acids and amino acid derivatives in LDM4 lacking glucose (Fig. 5, Tables 3 and 5). Surprisingly, $B$. dentium could use 14 amino acids as sole carbon sources to support limited growth over short time periods $\leq 8.3 \mathrm{~h}\left(\mathrm{OD}_{600 \mathrm{~nm}}>0.2\right.$, representing growth) (Fig. 5a, b). These amino acids included D-aspartic acid, D-serine, D-threonine, L-alanine, L-asparagine, L-aspartic acid, L-glutamic acid, L-glutamine, L-serine, L-threonine, tyramine, Glycyl-L-aspartic acid, Glycyl-L-glutamic acid, and Glycyl-L-Proline. Next, we examined B. dentium on glycosides and specifically nucleosides (Fig. 6a-d). $B$. dentium had significant growth using amygdalin, arbutin and salicin (Fig. 6a, c), consistent with findings in pigs that these glycosides promote the growth of certain Bifidobacterium strains [62]. In contrast, no growth was observed with nucleosides (Fig. 6b, d), cyclodextrin polymers (Fig. 6e, h), or polysorbates (Fig. 6g, h). Interestingly, we observed no significant growth with several polysaccharides (Fig. 6f, h), including inulin, which has been shown in mouse studies and human clinical trials to lead to an increase in bifidobacteria [13, 63-68]. To simulate the diverse number of carbon sources in the GI tract, we supplemented inulin containing LDM4 with glucose and we observed that the combination of carbon sources supported more growth than glucose alone (at $2.5 \mathrm{~h}:$ LDM4 glucose control $\mathrm{OD}_{600 \mathrm{~nm}}=$ $0.39 \pm 0.11$, Inulin $=0.54 \pm 0.12$; mean \pm stdev). Finally, we analyzed the ability of $B$. dentium to grow with 59 different organic acid sources. Of the organic acids 
Table 5 Proteins identified in B. dentium ATCC 27678 by proteomic analysis

Pathway Description

Pathway Accession

\# Proteins

2-Oxocarboxylic acid metabolism

bde01210

2-Oxocarboxylic acid metabolism

bks01210

9

2-Oxocarboxylic acid metabolism

blf01210

9

2-Oxocarboxylic acid metabolism

blx01210

5

$A B C$ transporters

bln01210

bde02010

$A B C$ transporters

bks02010

$A B C$ transporters

blf02010

Acarbose and validamycin biosynthesis

bks00525

Acarbose and validamycin biosynthesis

bde00525

Acarbose and validamycin biosynthesis

boa00525

Alanine, aspartate and glutamate metabolism

bde00250

1

Alanine, aspartate and glutamate metabolism

bks00250

Alanine, aspartate and glutamate metabolism

blf00250

Alanine, aspartate and glutamate metabolism

bln00250

Amino sugar and nucleotide sugar metabolism

bde00520

Amino sugar and nucleotide sugar metabolism

bks00520

Amino sugar and nucleotide sugar metabolism

blf00520

Amino sugar and nucleotide sugar metabolism

bln00520

Amino sugar and nucleotide sugar metabolism

boa00520

Aminoacyl-tRNA biosynthesis

bde00970

Aminoacyl-tRNA biosynthesis

bks00970

Aminoacyl-tRNA biosynthesis

blf00970

Aminoacyl-tRNA biosynthesis

bln00970

Aminoacyl-tRNA biosynthesis

boa00970

Arginine biosynthesis

bde00220

Arginine biosynthesis

bks00220

Arginine biosynthesis

blf00220

Arginine biosynthesis

bln00220

Bacterial secretion system

bde03070

Bacterial secretion system

bks03070

6

Bacterial secretion system

blf03070

Bacterial secretion system

bln03070

beta-Alanine metabolism

bde00410

beta-Lactam resistance

bde01501

beta-Lactam resistance

blf01501

Biosynthesis of amino acids

bde01230

Biosynthesis of amino acids 
Table 5 Proteins identified in B. dentium ATCC 27678 by proteomic analysis (Continued)

\section{Pathway Description}

Biosynthesis of antibiotics

Biosynthesis of antibiotics

Biosynthesis of antibiotics

Biosynthesis of antibiotics

Biosynthesis of antibiotics

Biosynthesis of secondary metabolites

Biosynthesis of secondary metabolites

Biosynthesis of secondary metabolites

Biosynthesis of secondary metabolites

Biosynthesis of secondary metabolites

Biosynthesis of secondary metabolites

Biosynthesis of secondary metabolites

Butanoate metabolism

Butanoate metabolism

Butanoate metabolism

Butanoate metabolism

C5-Branched dibasic acid metabolism

C5-Branched dibasic acid metabolism

Carbon metabolism

Carbon metabolism

Carbon metabolism

Carbon metabolism

Carbon metabolism

Chloroalkane and chloroalkene degradation

Chloroalkane and chloroalkene degradation

Citrate cycle (TCA cycle)

Citrate cycle (TCA cycle)

Citrate cycle (TCA cycle)

Citrate cycle (TCA cycle)

Cyanoamino acid metabolism

Cyanoamino acid metabolism

Cysteine and methionine metabolism

Cysteine and methionine metabolism

Cysteine and methionine metabolism

Cysteine and methionine metabolism

Cysteine and methionine metabolism

Degradation of aromatic compounds

Degradation of aromatic compounds

DNA replication

DNA replication

Fatty acid biosynthesis

Fatty acid biosynthesis

Fatty acid biosynthesis

Fatty acid biosynthesis

\section{Pathway Accession}

blf01130

bln01130

boa01130

blx01130

blm01130

bde01110

bks01110

blf01110

bln01110

boa01110

blx01110

blm01110

bde00650

bks00650

blf00650

boa00650

bde00660

bks00660

bde01200

bks01200

blf01200

boa01200

bln01200

bks00625

bde00625

bde00020

bks00020

boa00020

blf00020

bde00460

boa00460

bde00270

bks00270

blf00270

boa00270

blm00270

bks01220

bde01220

bde03030

bks03030

boa00061

bks00061

blf00061

bde00061

\section{\# Proteins}

19

9

7

2

1

62

37

24

10

8

2

1

4

2

1

1

4

3

25

15

10

5

3

1

1

5

2

2

1

1

1

8

6

3

2

1

1

1

2

1

2 
Table 5 Proteins identified in B. dentium ATCC 27678 by proteomic analysis (Continued)

\section{Pathway Description}

Fatty acid degradation

Fatty acid degradation

Fatty acid metabolism

Fatty acid metabolism

Fatty acid metabolism

Fatty acid metabolism

Fructose and mannose metabolism

Fructose and mannose metabolism

Fructose and mannose metabolism

Galactose metabolism

Galactose metabolism

Galactose metabolism

Galactose metabolism

Glutathione metabolism

Glutathione metabolism

Glutathione metabolism

Glycerolipid metabolism

Glycerolipid metabolism

Glycerolipid metabolism

Glycerophospholipid metabolism

Glycerophospholipid metabolism

Glycerophospholipid metabolism

Glycerophospholipid metabolism

Glycine, serine and threonine metabolism

Glycine, serine and threonine metabolism

Glycine, serine and threonine metabolism

Glycine, serine and threonine metabolism

Glycine, serine and threonine metabolism

Glycolysis / Gluconeogenesis

Glycolysis / Gluconeogenesis

Glycolysis / Gluconeogenesis

Glycolysis / Gluconeogenesis

Glycolysis / Gluconeogenesis

Glycolysis / Gluconeogenesis

Glyoxylate and dicarboxylate metabolism

Glyoxylate and dicarboxylate metabolism

Glyoxylate and dicarboxylate metabolism

Histidine metabolism

Histidine metabolism

Homologous recombination

Homologous recombination

Inositol phosphate metabolism

Inositol phosphate metabolism

Inositol phosphate metabolism
Pathway Accession

bks00071

bde00071

boa01212

bks01212

blf01212

bde01212

bde00051

bks00051

boa00051

bde00052

bks00052

blf00052

boa00052

bde00480

bks00480

blf00480

bks00561

blf00561

bde00561

bde00564

bks00564

blf00564

bln00564

bde00260

bks00260

bln00260

blf00260

boa00260

bde00010

bks00010

blf00010

bln00010

boa00010

blm00010

bde00630

bks00630

blf00630

blf00340

bde00340

bde03440

bks03440

boa00562

bks00562

bde00562
\# Proteins

1

2

1

1

1

2

1

1

6

4

3

1

3

2

1 
Table 5 Proteins identified in B. dentium ATCC 27678 by proteomic analysis (Continued)

\section{Pathway Description}

Lipopolysaccharide biosynthesis

Lysine biosynthesis

Lysine biosynthesis

Metabolic pathways

Metabolic pathways

Metabolic pathways

Metabolic pathways

Metabolic pathways

Metabolic pathways

Metabolic pathways

Methane metabolism

Methane metabolism

Methane metabolism

Methane metabolism

Methane metabolism

Microbial metabolism in diverse environments

Microbial metabolism in diverse environments

Microbial metabolism in diverse environments

Microbial metabolism in diverse environments

Microbial metabolism in diverse environments

Microbial metabolism in diverse environments

Mismatch repair

Mismatch repair

Monobactam biosynthesis

Monobactam biosynthesis

Naphthalene degradation

Naphthalene degradation

Nicotinate and nicotinamide metabolism

Nicotinate and nicotinamide metabolism

Nicotinate and nicotinamide metabolism

Nitrogen metabolism

Nitrogen metabolism

Nitrogen metabolism

One carbon pool by folate

One carbon pool by folate

One carbon pool by folate

Other glycan degradation

Oxidative phosphorylation

Oxidative phosphorylation

Oxidative phosphorylation

Oxidative phosphorylation

Oxidative phosphorylation

Oxidative phosphorylation

Pantothenate and CoA biosynthesis
Pathway Accession

boa00540

bde00300

bks00300

bde01100

bks01100

blf01100

boa01100

bln01100

blx01100

blm01100

bde00680

bks00680

bln00680

blf00680

boa00680

bde01120

bks01120

blf01120

boa01120

bln01120

blm01120

bde03430

bks03430

bks00261

bde00261

bks00626

bde00626

blf00760

bks00760

bde00760

bde00910

bks00910

blf00910

blf00670

bde00670

bks00670

bde00511

bde00190

bks00190

blx00190

blf00190

bln00190

boa00190

bde00770
\# Proteins

3

118

71

48

19

17

7

1

7

4

2

2

1

36

24

13

6

3

1

3

2

2

2

1

1

2

2

2

3

2

2

2

2

1

1

9

6

5

4

3

2

6 
Table 5 Proteins identified in B. dentium ATCC 27678 by proteomic analysis (Continued)

\section{Pathway Description}

Pantothenate and CoA biosynthesis

Pantothenate and CoA biosynthesis

Pantothenate and CoA biosynthesis

Pantothenate and COA biosynthesis

Pantothenate and COA biosynthesis

Pentose and glucuronate interconversions

Pentose and glucuronate interconversions

Pentose and glucuronate interconversions

Pentose phosphate pathway

Pentose phosphate pathway

Pentose phosphate pathway

Peptidoglycan biosynthesis

Peptidoglycan biosynthesis

Peptidoglycan biosynthesis

Phenylalanine, tyrosine and tryptophan biosynthesis

Phenylalanine, tyrosine and tryptophan biosynthesis

Phenylalanine, tyrosine and tryptophan biosynthesis

Phosphotransferase system (PTS)

Phosphotransferase system (PTS)

Polyketide sugar unit biosynthesis

Polyketide sugar unit biosynthesis

Polyketide sugar unit biosynthesis

Porphyrin and chlorophyll metabolism

Propanoate metabolism

Propanoate metabolism

Propanoate metabolism

Propanoate metabolism

Protein export

Protein export

Protein export

Protein export

Purine metabolism

Purine metabolism

Purine metabolism

Purine metabolism

Purine metabolism

Purine metabolism

Pyrimidine metabolism

Pyrimidine metabolism

Pyrimidine metabolism

Pyrimidine metabolism

Pyrimidine metabolism

Pyrimidine metabolism

Pyruvate metabolism
Pathway Accession

bks00770

blf00770

blx00770

bln00770

boa00770

bde00040

blf00040

bks00040

bde00030

bks00030

blf00030

bde00550

bks00550

blf00550

bde00400

blf00400

bks00400

bks02060

bde02060

bks00523

bde00523

boa00523

bde00860

bde00640

bks00640

blf00640

blm00640

bde03060

bks03060

blf03060

bln03060

bde00230

bks00230

blf00230

bln00230

blx00230

boa00230

bde00240

bks00240

blf00240

bln00240

boa00240

blx00240

bde00620
\# Proteins

4

3

1

1

1

4

1

1

10

6

5

4

1 
Table 5 Proteins identified in B. dentium ATCC 27678 by proteomic analysis (Continued)

\begin{tabular}{|c|c|c|}
\hline Pathway Description & Pathway Accession & \# Proteins \\
\hline Pyruvate metabolism & bks00620 & 5 \\
\hline Pyruvate metabolism & boa00620 & 3 \\
\hline Pyruvate metabolism & blf00620 & 2 \\
\hline Pyruvate metabolism & blm00620 & 1 \\
\hline Quorum sensing & bde02024 & 17 \\
\hline Quorum sensing & bks02024 & 5 \\
\hline Quorum sensing & blf02024 & 4 \\
\hline Quorum sensing & bln02024 & 1 \\
\hline Riboflavin metabolism & boa00740 & 1 \\
\hline Ribosome & bde03010 & 47 \\
\hline Ribosome & bks03010 & 17 \\
\hline Ribosome & bln03010 & 15 \\
\hline Ribosome & blf03010 & 14 \\
\hline Ribosome & boa03010 & 10 \\
\hline Ribosome & blx03010 & 5 \\
\hline RNA degradation & bde03018 & 6 \\
\hline RNA degradation & bln03018 & 4 \\
\hline RNA degradation & bks03018 & 4 \\
\hline RNA degradation & blf03018 & 3 \\
\hline RNA degradation & boa03018 & 2 \\
\hline RNA degradation & bad03018 & 1 \\
\hline RNA polymerase & bde03020 & 4 \\
\hline RNA polymerase & bks03020 & 3 \\
\hline RNA polymerase & blf03020 & 2 \\
\hline RNA polymerase & blx03020 & 1 \\
\hline RNA polymerase & bln03020 & 1 \\
\hline Secondary bile acid biosynthesis & bks00121 & 1 \\
\hline Secondary bile acid biosynthesis & bde00121 & 1 \\
\hline Selenocompound metabolism & bde00450 & 2 \\
\hline Selenocompound metabolism & bks00450 & 1 \\
\hline Selenocompound metabolism & blf00450 & 1 \\
\hline Sphingolipid metabolism & bde00600 & 1 \\
\hline Starch and sucrose metabolism & bde00500 & 11 \\
\hline Starch and sucrose metabolism & bks00500 & 6 \\
\hline Starch and sucrose metabolism & blf00500 & 4 \\
\hline Starch and sucrose metabolism & boa00500 & 2 \\
\hline Starch and sucrose metabolism & bln00500 & 1 \\
\hline Streptomycin biosynthesis & bks00521 & 3 \\
\hline Streptomycin biosynthesis & bde00521 & 3 \\
\hline Streptomycin biosynthesis & boa00521 & 2 \\
\hline Streptomycin biosynthesis & blf00521 & 1 \\
\hline Taurine and hypotaurine metabolism & bde00430 & 3 \\
\hline Taurine and hypotaurine metabolism & bks00430 & 2 \\
\hline Taurine and hypotaurine metabolism & blf00430 & 1 \\
\hline
\end{tabular}


Table 5 Proteins identified in B. dentium ATCC 27678 by proteomic analysis (Continued)

\begin{tabular}{lll}
\hline Pathway Description & Pathway Accession & \# Proteins \\
\hline Thiamine metabolism & bde00730 & 1 \\
Two-component system & bde02020 & 4 \\
Two-component system & blf02020 & 2 \\
Two-component system & bks02020 & 1 \\
Tyrosine metabolism & bks00350 & 1 \\
Tyrosine metabolism & bde00350 & 1 \\
Valine, leucine and isoleucine biosynthesis & bde00290 & 7 \\
Valine, leucine and isoleucine biosynthesis & bks00290 & 4 \\
Valine, leucine and isoleucine biosynthesis & blf00290 & 3 \\
Valine, leucine and isoleucine biosynthesis & blx00290 \\
Valine, leucine and isoleucine biosynthesis & bln00290 \\
Valine, leucine and isoleucine degradation & bde00280 \\
Valine, leucine and isoleucine degradation & bks00280 \\
Valine, leucine and isoleucine degradation & blf00280 \\
Vancomycin resistance & bde01502 \\
Vitamin B6 metabolism & bde00750 & 1 \\
\hline
\end{tabular}

examined, B. dentium growth was only stimulated to statistical significance by D-glucuronic acid (Fig. 7a-f). These data point to the metabolic flexibility of $B$. dentium to use select amino acids, glycosidases and organic acids to support microbial growth in the absence of a carbohydrate source.

These findings of metabolic functionality are supported by our proteomic analysis of B. dentium ATCC 27678 from LDM4 cultures using glucose as a primary carbon source (Fig. 8, Table 5). Of the 319 proteins we identified, $52(16.3 \%)$ were involved in metabolic pathways and $15(4.7 \%)$ were involved in metabolism in diverse environments. We observed several proteins involved in carbon metabolism (3.4\%), purine metabolism $(2.5 \%)$, amino sugar and nucleotide sugar metabolism (1.6\%), glycine/serine/threonine metabolism (1.6\%), cysteine/methionine metabolism (1.6\%), pyruvate metabolism (1.3\%), starch and sucrose metabolism (1.3\%) and

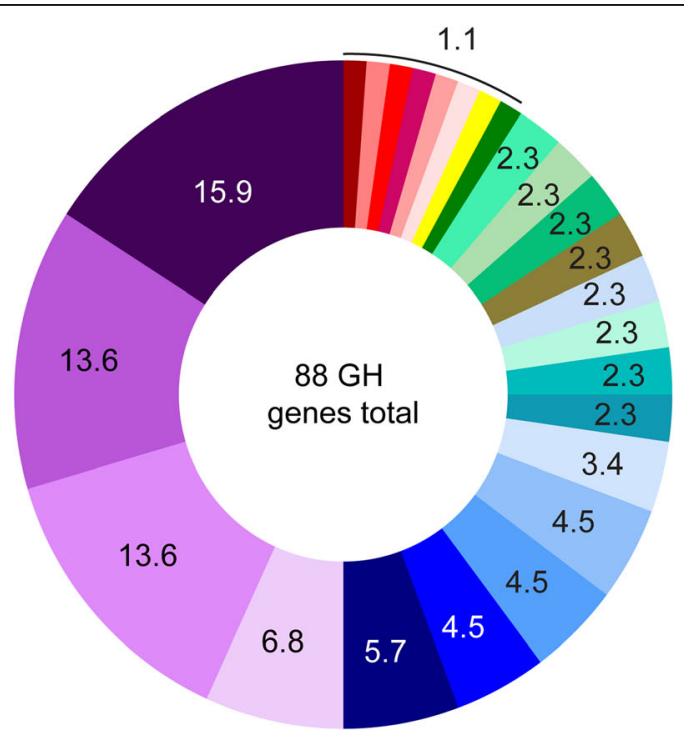

$\begin{array}{ll}\text { GH27 } & \text { GH53 } \\ \text { GH29 } & \text { GH77 } \\ \text { GH30 } & \text { GH127 } \\ \text { GH78 } & \text { GH23 } \\ \text { GH94 } & \text { GH5 } \\ \text { GH121 } & \text { GH31 } \\ \text { GH125 } & \text { GH42 } \\ \text { GHNC } & \text { GH36 } \\ \text { GH1 } & \mathrm{GH} 2 \\ \text { GH25 } & \mathrm{GH} 3 \\ \text { GH26 } & \text { GH43 } \\ \text { GH32 } & \mathrm{GH} 13 \\ \text { GH51 } & \end{array}$

Fig. 4 The B. dentium ATCC 27678 genome contains mulitple glycosyl hydrolase (GH) genes. The B. dentium ATCC 27678 genome was found to harbor $88 \mathrm{GH}$-related genes, encoding for 25 different $\mathrm{GH}$ families 


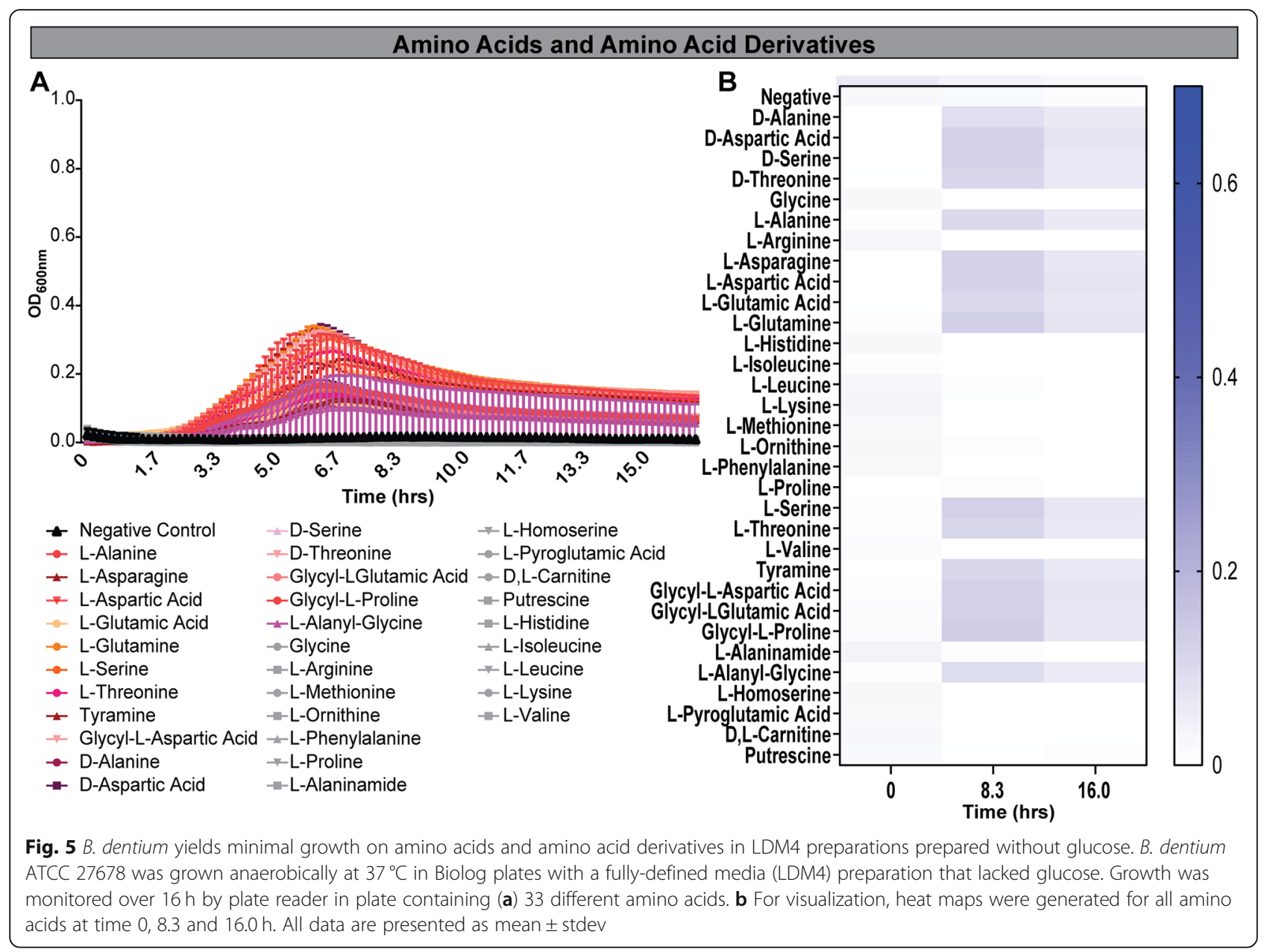

alanine/aspartate/glutamate metabolism (0.9\%). Consistent with our genome analysis, we observed proteins involved in the pentose phosphate pathway $(1.3 \%)$ and large number of $\mathrm{ABC}$ transporters (4.3\%). Together these findings indicate that $B$. dentium can metabolize a wide range of growth substrates, including nutrient sources that are commonly found in the human diet and in the gut lumen.

\section{Discussion}

The human GI tract is a highly competitive environment characterized by fluctuations in nutrient source availability. As a result, metabolic versatility, which allows microbes to use multiple carbon, nitrogen, and other sources, is characteristic of successful commensal microbes. In this study, we provide an in-depth analysis of $B$. dentium growth in a myriad of conditions, including varying acid conditions and nutrient sources (Fig. 9). We demonstrate that $B$. dentium can survive conditions which mirror the transit through the GI tract and adheres to intestinal mucus, indicating adaptation as a commensal member of the GI tract. The data gathered in this study also provide a substantial amount of information on the growth-promoting properties of B. dentium. We demonstrate that in the absence of glucose, $B$. dentium can still use 14 sugars, 4 amino acids/amino acid derivatives/amines, 3 glycosides, and 1 organic acid to support its growth. These data reveal metabolic flexibility in nutrient utilization in $B$. dentium, which likely is key to successful competition in the dynamic intestinal milieu. Despite some carbon sources supporting only modest/or short-term growth, according to Rolf Freter's nutrient niche hypothesis, we interpret this finding as being both a necessary and a sufficient component of $B$. dentium ecological fitness in the GI tract. It is highly unlikely that long term carbon utilization will depend on any single source in vivo, but short-term utilization of variable and transient nutrients is critical to successful colonization [69-71]. The data presented demonstrate $B$. dentium's ability to grow and thrive under varying conditions found in the gastrointestinal tract. These findings enlighten our understanding of the diverse sources that regulate $B$. dentium's ability to colonize the human intestine. 

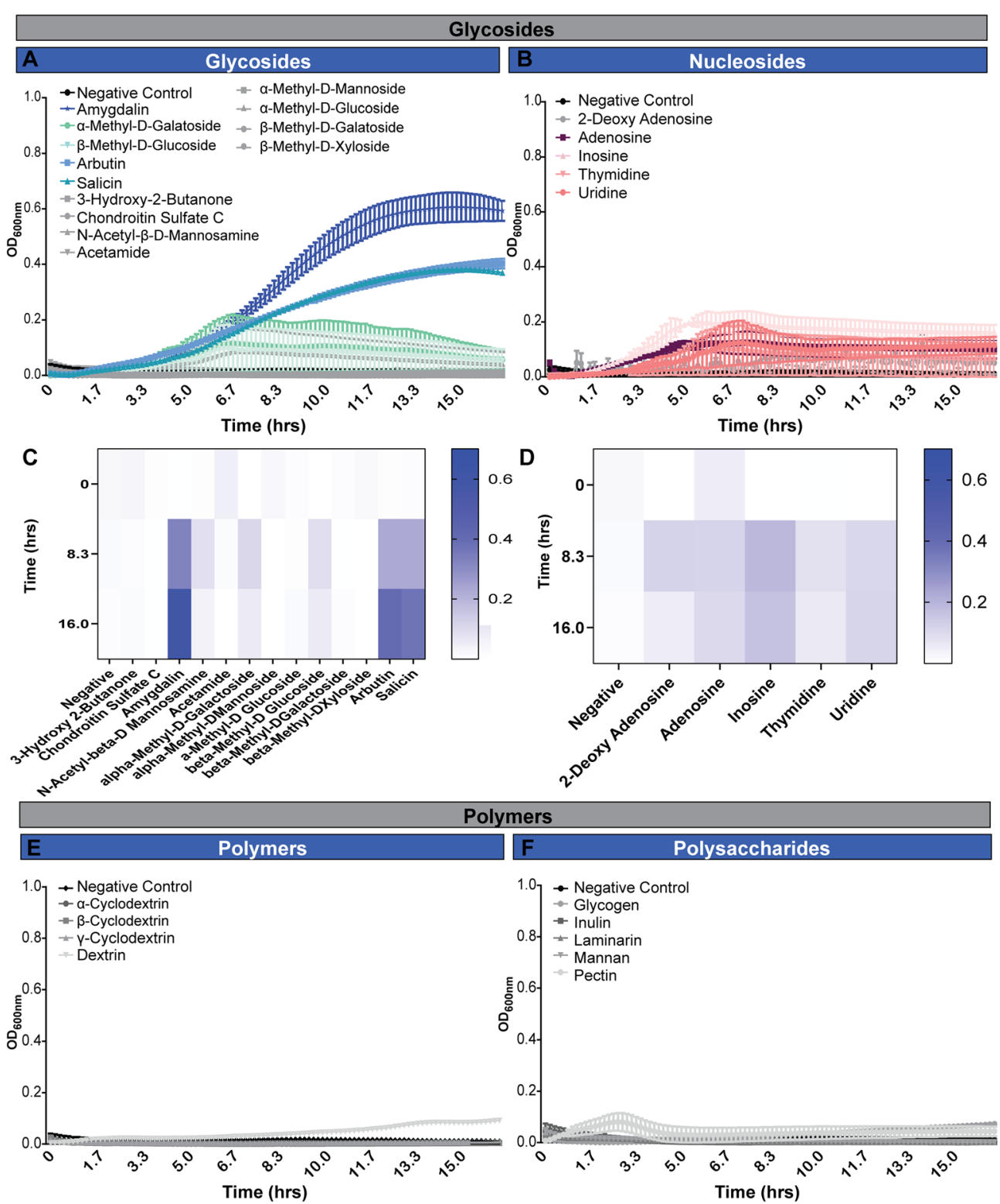

Polymers
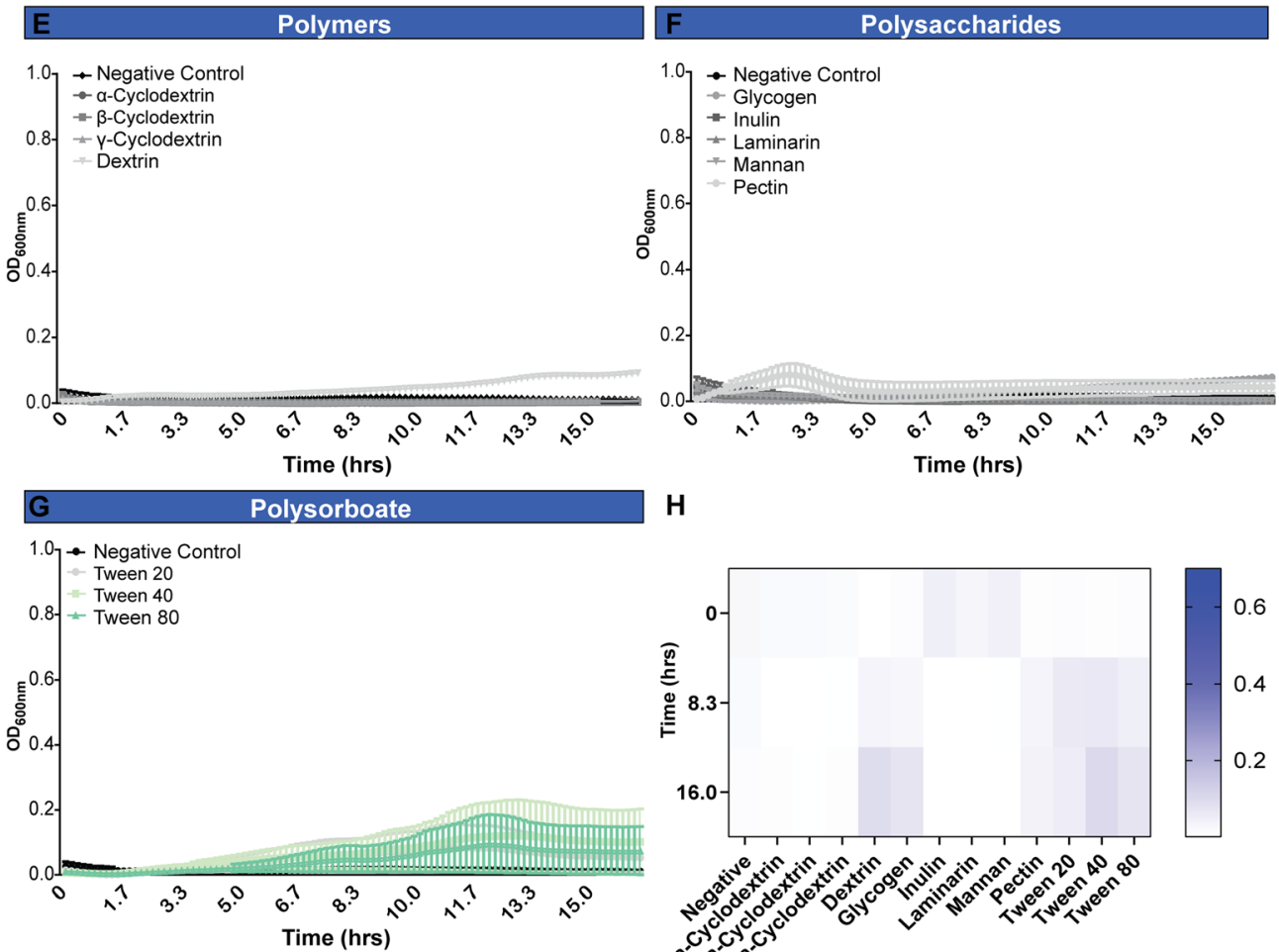

H

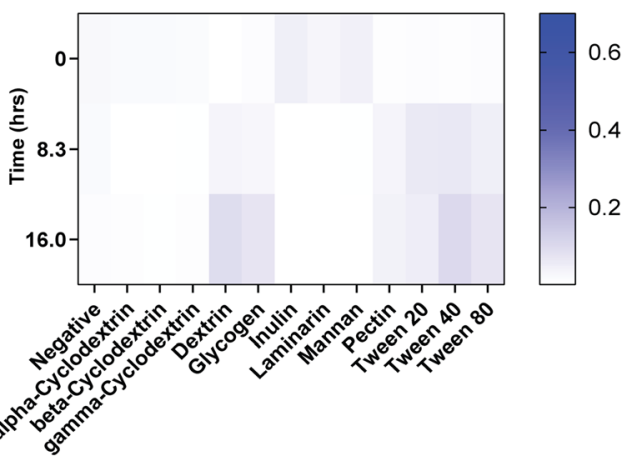

Fig. 6 (See legend on next page.) 
(See figure on previous page.)

Fig. 6 B. dentium does not grow on glycosides, nucleosides, polymers, polysaccharides or polysorbates in the absence of glucose, with the exception of amygdalin, arbutin and salicin. B. dentium ATCC 27678 was grown anaerobically at $37^{\circ} \mathrm{C}$ in Biolog plates with a fully-defined media (LDM4) preparation that lacked glucose. Growth was monitored over $16 \mathrm{~h}$ by plate reader in plate containing a glycosides, $\mathbf{b}$ nucleosides. Heat maps were generated for $\mathbf{c}$ glycosides and $\mathbf{d}$ nucleosides at time $0,8.3$ and $16 \mathrm{~h}$. B. dentium growth was also monitored with $\mathbf{e}$ polymers, $\mathbf{f}$ polysaccharides, and $\mathbf{g}$ polysorbates. $\mathbf{h}$ For visualization, heat maps were generated for polymers, polysaccharides and polysorbates at time $0,8.3$ and $16.0 \mathrm{~h}$. All data are presented as mean \pm stdev

Like other bifidobacteria, $B$. dentium is a recognized member of the infant and adult intestinal microbiome $[3,6-8,37]$. However, $B$. dentium species are also members of the oral microbiome and have been identified in dental caries [33, 50, 72-81]. In addition to B. dentium, $B$. breve, $B$. adolescentis, and $B$. longum have also been isolated from dental caries [33, 50, 72-81]. Although the precise role bifidobacteria plays in dental caries is unknown, Bifidobacterium species may be bystanders due to their adhesive properties and their resistance to acidity [50, 82-84]. In gnotobiotic animals, $B$. dentium was found to have beneficial effects on the host, with no adverse effects noted [21-23, 42]; suggesting that $B$. dentium also participates as a commensal intestinal microbe.

Dealing with acid stress is an important factor for colonizing gut microbes. Acid tolerance in bifidobacteria has been linked to the activity of the membrane $\mathrm{H}+$ F1F0-ATPase [53, 85]. The H + -F1F0-ATPase enzyme is responsible for maintaining $\mathrm{pH}$ homeostasis in most anaerobic microbes. Acid-resistant Bifidobacterium species like $B$. animalis activate the F1F0-ATPase complex upon acid exposure [86, 87]. B. dentium encodes the genes for the $\mathrm{H}+$-F1F0-ATPase (KEGG) and based on the relative resistance of $B$. dentium to low $\mathrm{pH}$, we speculate that the $\mathrm{H}+\mathrm{F} 1 \mathrm{~F} 0-\mathrm{ATPase}$ is likely activated. In B. longum, low extracellular $\mathrm{pH}$ is reflected by a low intracellular $\mathrm{pH}$ [85]. Similar to the literature, our data indicate that $B$. dentium's intracellular $\mathrm{pH}$ can reach a low level without a significant loss in viability. Although these experiments were performed in rich bacterial media, we speculate that $B$. dentium would survive the transit of the gastrointestinal tract. Together, these findings suggest that $B$. dentium harbors compensatory mechanisms to withstand the various pHs of the gastrointestinal tract.

Nutrient availability may be limited in the intestinal lumen due to a variety of factors including competition by other microbes, absorption by the host, or transit through the GI system. Therefore, metabolic plasticity is key to successful microbial colonization. Recent analysis of multiple oral and intestinal derived B. dentium genomes identified 140 conserved genes among $B$. dentium strains, indicating a high degree of phylogenetic relatedness [88]. All B. dentium genomes shared 19 glycosyl hydrolases families, with the highest abundance observed in GH13. This is consistent with our B. dentium ATCC 27678 analysis, which revealed the highest expression of GH13. The glycobiome of $B$. dentium strains also indicated a degradation of a wide range of carbohydrates and plant-derived polysaccharides [88]. Using Biolog phenotyping arrays, we identified that in the absence of glucose, B. dentium ATCC 27678 readily uses mannose, xylose, mannitol, maltose, sucrose, melibiose, gentiobiose, trunose, raffinose, maltotriose, and stachyose, Sedoheptulosan. We also observed growth with galactose, which supports previous work indicating that galacto-oligosaccharides (GOS) supplementation bolsters the abundance of bifidobacteria [1, 2, 89]. This is also consistent with the $B$. dentium ATCC 27678 genome, which contains the $\mathrm{GH}$ enzyme for $\beta$-galactosidases (GH2 and GH42 families), likely allowing B. dentium to grow on galacto-oligosaccharides.

Interestingly, we found that in the absence of glucose, B. dentium was unable to use several polysaccharides which normally promote bifidobacterial growth. These included well characterized inulin, lactulose, and pectin. Prebiotic substrates, in particular inulin and lactulose, have been used in human trials where they have been observed to increase Bifidobacterium spp. and provide beneficial effects to the host [13, 36, 90-93]. The addition of glucose back into the LDM4 preparation in our studies showed that B. dentium ATCC 27678 growth was enhanced with inulin, confirming the dependence on glucose for inulin metabolism [63].

We also observed that in the absence of glucose, $B$. dentium was able to use amino acids to support baseline growth. Limited data are available on nitrogen assimilation in the gut lumen, particularly by Bifidobacterium species [94]. Herein, we provide evidence for metabolism of select amino acids in lieu of a carbohydrate-based carbon source which can be used as carbon or nitrogen substrates as needed. We also found that B. dentium was largely unable to use host glycan sugars. This finding is consistent with the $\mathrm{GH}$ profile of $B$. dentium and our previous work which found that $B$. dentium could not degrade intact MUC2 mucus [42]. Other bifidobacteria, such as B. bifidum (PRL2010, D119 and L22), B. breve NCIMB8807, and B. longum NCIMB8809, harbor a much larger repertoire of mucin-degrading glycosyl hydrolases [95-99]. These mucin- and HMO-degrading 


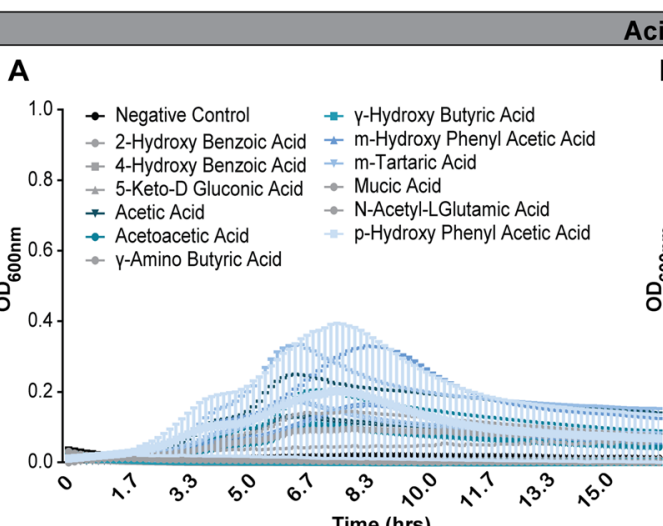

\section{Acids}

\section{B}

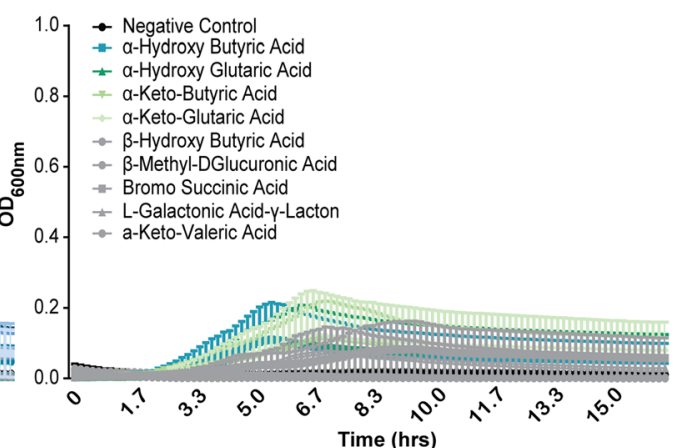

C

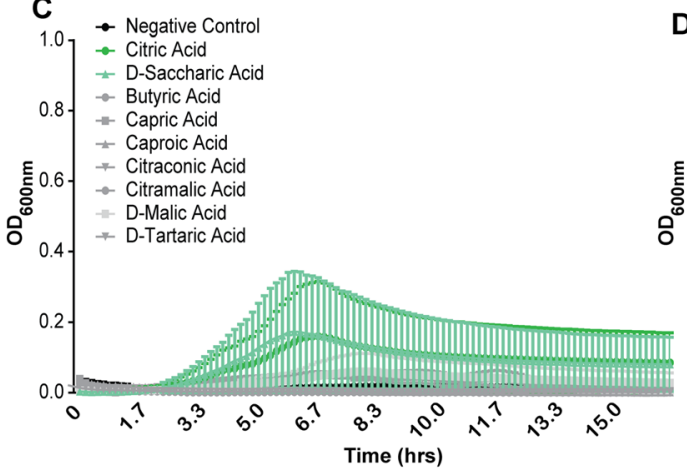

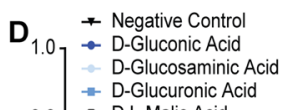

$0.8-$ D,L-Malic Acid

- $\delta$-Amino Valeric Acid

- D-Galactonic Acid-y-Lacton

- D-Galactonic Acid-y-

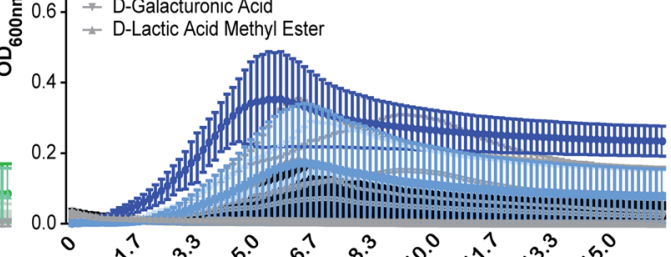

E

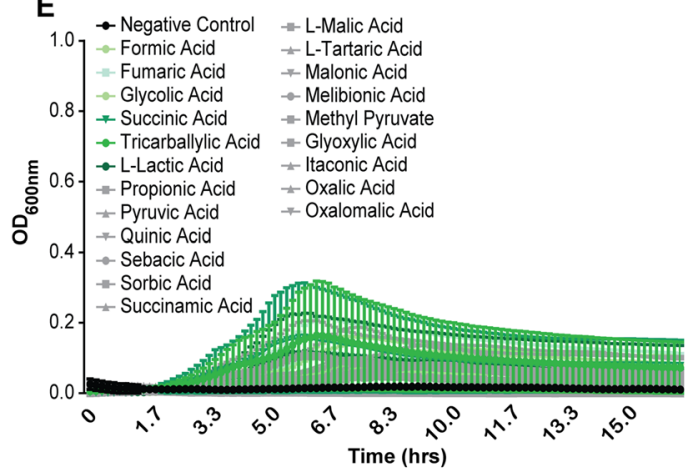

F

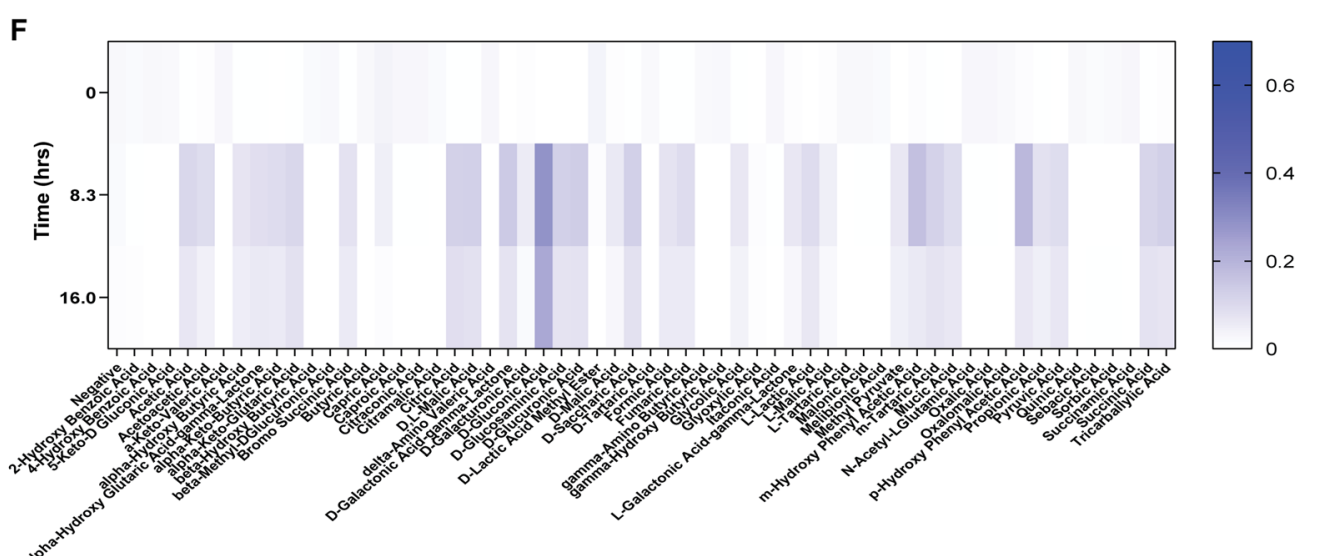

Fig. 7 (See legend on next page.) 
(See figure on previous page.)

Fig. 7 B. dentium has minimal growth on organic acids without glucose. B. dentium ATCC 27678 was grown anaerobically at $37^{\circ} \mathrm{C}$ in Biolog plates with a fully-defined media (LDM4) preparation that lacked glucose. Growth was monitored over $16 \mathrm{~h}$ by plate reader in plate containing 59 different organic acids. Acids were separated into groups: a 12 acids, b 9, c 9, d 8 and e 21 acids. f Heat maps were generated for organic acids at time $0,8.3$ and $16.0 \mathrm{~h}$. All data are presented as mean \pm stdev

GHs likely provide these Bifidobacterium strains with a competitive edge, allowing these microbes to be found at greater abundance than $B$. dentium in vivo.

Consistent with GHs profile, we found that $B$. dentium exhibited substantial growth on $\beta$-glucans. $B$. dentium harbors GH 1,3 and 30 which harbor $\beta$ glucosidases which can degrade plant based $\beta$-glucans and natural phenols, such as salicin, arbutin and amygdalin. Additionally, $B$. dentium had robust growth on these $\beta$-glucans, indicating that $B$. dentium may target plant-based nutrients. Our in vitro findings indicate that $B$. dentium supports it growth with several plantderived compounds which closely mirrors dietary studies in humans. For example, consumption of pea and whey protein extract increases bifidobacteria levels in healthy subjects [100-102]. Consumption of date fruits, containing high levels of glucose, fructose, and sucrose, has also been reported to increase the relative abundance of bifidobacteria [103-105]. Diets rich in non-digestible carbohydrates, such as whole grain and wheat bran, are also linked to increases in bifidobacteria $[106,107]$. In contrast, a Western diet (high in animal protein and fat, low in fiber) has been associated with decreased bifidobacteria [108-110]. These human studies support the important role of dietary compounds in modulating the microbial community and influencing the levels of bifidobacteria. Bifidobacteria have been associated with numerous health benefits, including immune-modulation, gut-brain-axis crosstalk, increasing intestinal mucus, enhancing epithelial integrity, pathogen exclusion, cancer prevention, and management of inflammatory bowel disease [16, 21, 23,

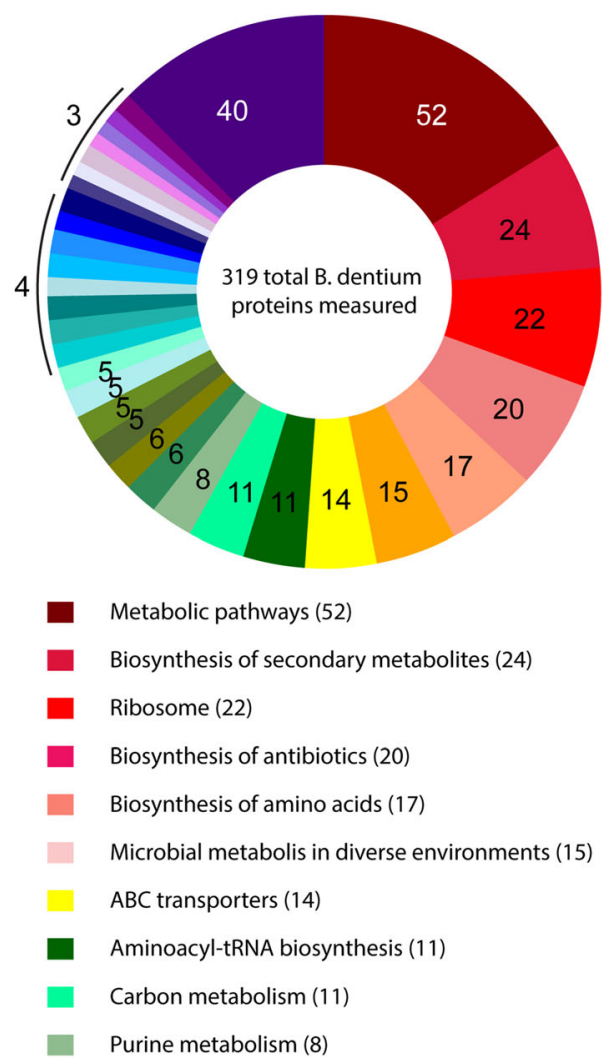

Quorum sensing (6)

Pyrimidine metabolism (6)

Protein export (5)

- Amino sugar and nucleotide sugar metabolism (5)

Glycine, serine and threonine metabolism (5)

Cysteine and methionine metabolism (5)

Oxidative phosphorylation (4)

2-Oxocarboxylic acid metabolism (4)

RNA degradation (4)

Glycerophospholipid metabolism (4)

Pyruvate metabolism (4)

Bacterial secretion system (4)

- Starch and sucrose metabolism (4)

- Pentose phosphate pathway (4)

- Alanine, aspartate and glutamate metabolism (3)

Mismatch repair (3)

Peptidoglycan biosynthesis (3)

Arginine biosynthesis (3)

Lysine biosynthesis (3)

- Glycolysis / Gluconeogenesis (3)

- Methane metabolism (3)

- Other protein classifications (40)

Fig. 8 Pathway analysis B. dentium by proteomic analysis. B. dentium ATCC 27678 were examined using high-resolution liquid chromatographytandem mass spectrometry based proteomics and 319 proteins were identified from $B$. dentium. The functional classifications of these proteins are illustrated in the pie chart above 


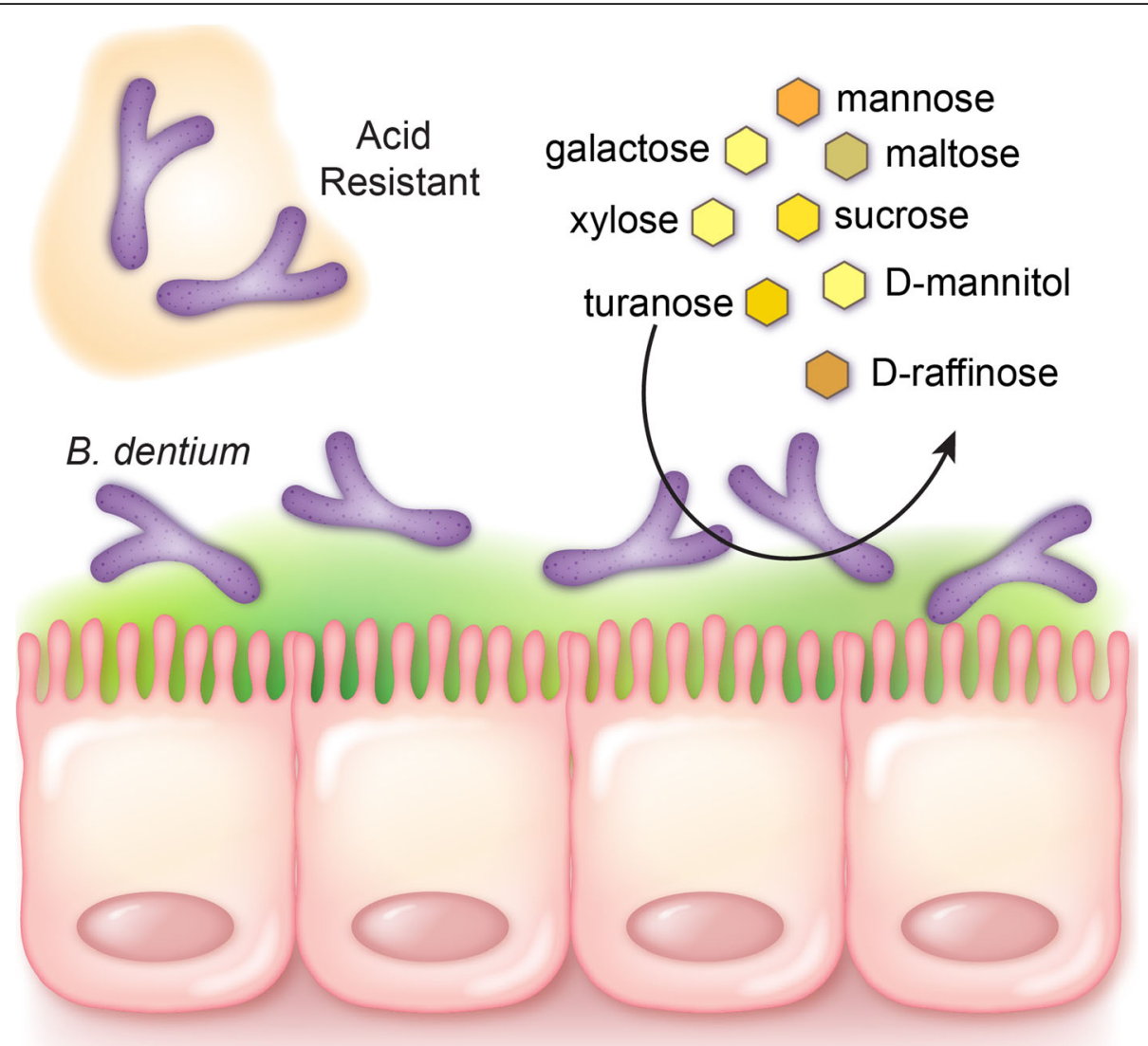

Fig. 9 Proposed model for $B$. dentium intestinal colonization. Our data suggest that $B$. dentium is acid resistant, adheres to the intestinal mucus layer and consumes a variety of dietary sources. We speculate that these features contribute to the ability of $B$. dentium to colonize the intestine

38, 42, 93, 111-143]. Thus, maintenance of bifidobacteria is likely important for maintaining intestinal homeostasis. Based on our newly identified nutrient sources for $B$. dentium, we propose that these compounds could be implemented in the future to promote $B$. dentium abundance in the human gastrointestinal tract. Collectively this work provides novel insights into the proteome and metabolic profile of $B$. dentium and our findings point to $B$. dentium as a well-adapted member of the gastrointestinal tract.

\section{Supplementary Information}

The online version contains supplementary material available at https://doi. org/10.1186/s12866-021-02166-6.

\section{Additional file 1.}

\section{Authors' contributions}

Concept and design (MAE, JV); intellectual contribution (MAE, HAD, AH, KAE, $\mathrm{TDH}, \mathrm{SJH}, \mathrm{KMH}, \mathrm{BTE}, \mathrm{MB}, \mathrm{KWG}, \mathrm{RAB}, \mathrm{JKS}, \mathrm{AMH}$, JV); data acquisition (MAE, HAD, AH, KAE, TDH, SJH, KMH, BTE); data analysis, statistics, and interpretation (MAE, HAD, AH, KAE, TDH, SJH, KMH, BTE, MB, KWG, JKS, AMH); drafting manuscript (MAE); editing manuscript (MAE, HAD, AH, KAE, TDH, SJH, KMH, $B T E, M B, K W G, R A B, J K S, A M H, J V$ ) funding (MAE, RAB, JKS, JV). The author(s) read and approved the final manuscript.

\section{Funding}

This work was supported by grants from the National Institute of Diabetes and Digestive and Kidney Diseases (Grant P30DK56338 to Texas Medical Center Digestive Disease Center) (JKS, JV), K01DK12319501 (MAE), F32Al136404 (HAD), T32DK00766428 (KAE), U01Al124290 (RAB), and R01Al123278 (RAB) and through funding from Global Probiotic Council 2019-19319 (MAE). Unrestricted research support was also provided by BioGaia AB (Stockholm, Sweden) (JKS, RAB, JV).

\section{Availability of data and materials}

The datasets generated in the current study are deposited in the $\mathrm{NIH}$-funded Center for Computational Mass Spectrometry MassIVE database, Dataset Number MSV000086294.

Link: massive.ucsd.edu/ProteoSAFe/private-dataset.jsp?task= 9e9343b12d3540e7bc8c470f2de719d3.

\section{Declarations}

Ethics approval and consent to participate Not applicable.

\section{Consent for publication}

Not applicable.

\section{Competing interests}

J. Versalovic serves on the scientific advisory boards of Biomica, Plexus Worldwide and Seed Health. R.A. Britton serves on the scientific advisory board of Tenza, is a co-founder of Mikrovia, and consults for Takeda and Probiotech. J. Versalovic, J.K. Spinler, and R.A. Britton have received unrestricted research support from BioGaia, AB. The remaining authors have no commercial or financial relationships that could be construed as a potential conflict of interest. 


\section{Author details}

'Department of Pathology and Immunology, Baylor College of Medicine, Houston, TX, USA. ${ }^{2}$ Department of Pathology, Texas Children's Hospital, Houston, TX, USA. ${ }^{3}$ Department of Regernative Medicine \& Cell Biology, Medical University of South Carolina, SC, Charleston, USA. ${ }^{4}$ Department of Virology and Microbiology, Baylor College of Medicine, Houston, TX, USA. ${ }^{5}$ Department of Pharmacy Practice and Translational Research, University of Houston College of Pharmacy, Houston, TX, USA. ${ }^{6}$ Department of Chemistry and Physics, and Department of Biotechnology, Alcorn State University, Lorman, MS 39096, USA.

\section{Received: 18 November 2020 Accepted: 30 March 2021} Published online: 24 May 2021

\section{References}

1. Ben XM, Li J, Feng ZT, Shi SY, Lu YD, Chen R, et al. Low level of galactooligosaccharide in infant formula stimulates growth of intestinal Bifidobacteria and lactobacilli. World J Gastroenterol. 2008;14(42):6564-8. https://doi.org/10.3748/wjg.14.6564.

2. Fanaro S, Marten B, Bagna R, Vigi V, Fabris C, Pena-Quintana L, et al. Galacto-oligosaccharides are bifidogenic and safe at weaning: a doubleblind randomized multicenter study. J Pediatr Gastroenterol Nutr. 2009; 48(1):82-8. https://doi.org/10.1097/MPG.0b013e31817b6dd2.

3. He M, Li M, Wang SY, Zhang LL, Miao JJ, Shi L, et al. Analyzing colonization of Bifidobacteria in infants with real-time fluorescent quantitative PCR. Sichuan Da Xue Xue Bao Yi Xue Ban. 2016;47(4):527-32.

4. Kirmiz N, Robinson RC, Shah IM, Barile D, Mills DA. Milk Glycans and their interaction with the infant-gut microbiota. Annu Rev Food Sci Technol. 2018;9(1):429-50. https://doi.org/10.1146/annurev-food-030216-030207.

5. Lee JH, O'Sullivan DJ. Genomic insights into bifidobacteria. Microbiol Mol Biol Rev. 2010;74(3):378-416. https://doi.org/10.1128/MMBR.00004-10.

6. Nagpal R, Kurakawa T, Tsuji H, Takahashi T, Kawashima K, Nagata S, et al. Evolution of gut Bifidobacterium population in healthy Japanese infants over the first three years of life: a quantitative assessment. Sci Rep. 2017;7(1): 10097. https://doi.org/10.1038/s41598-017-10711-5.

7. Rinne MM, Gueimonde M, Kalliomaki M, Hoppu U, Salminen SJ, Isolauri E. Similar bifidogenic effects of prebiotic-supplemented partially hydrolyzed infant formula and breastfeeding on infant gut microbiota. FEMS Immunol Med Microbiol. 2005;43(1):59-65. https://doi.org/10.1016/j.femsim.2004.07.005.

8. Turroni F, Peano C, Pass DA, Foroni E, Severgnini M, Claesson MJ, et al. Diversity of bifidobacteria within the infant gut microbiota. PLoS One. 2012; 7(5):e36957. https://doi.org/10.1371/journal.pone.0036957.

9. Turroni F, Marchesi JR, Foroni E, Gueimonde M, Shanahan F, Margolles A, et al. Microbiomic analysis of the bifidobacterial population in the human distal gut. ISME J. 2009;3(6):745-51. https://doi.org/10.1038/ismej.2009.19.

10. Qin J, Li R, Raes J, Arumugam M, Burgdorf KS, Manichanh C, et al. A human gut microbial gene catalogue established by metagenomic sequencing. Nature. 2010;464(7285):59-65. https://doi.org/10.1038/nature08821.

11. Flint HJ, Bayer EA, Rincon MT, Lamed R, White BA. Polysaccharide utilization by gut bacteria: potential for new insights from genomic analysis. Nat Rev Microbiol. 2008;6(2):121-31. https://doi.org/10.1038/nrmicro1817.

12. Jasberg H, Soderling E, Endo A, Beighton D, Haukioja A. Bifidobacteria inhibit the growth of Porphyromonas gingivalis but not of Streptococcus mutans in an in vitro biofilm model. Eur J Oral Sci. 2016;124(3):251-8. https://doi.org/10.1111/eos.12266.

13. Kolida S, Tuohy K, Gibson GR. Prebiotic effects of inulin and oligofructose. $\mathrm{Br}$ J Nutr. 2002;87(Suppl 2):S193-7. https://doi.org/10.1079/BJNBJN/2002537.

14. O'Callaghan $A$, van Sinderen D. Bifidobacteria and their role as members of the human gut microbiota. Front Microbiol. 2016;7:925. https://doi.org/10.33 89/fmicb.2016.00925

15. Vazquez-Gutierrez P, de Wouters T, Werder J, Chassard C, Lacroix C. High iron-sequestrating Bifidobacteria inhibit Enteropathogen growth and adhesion to intestinal epithelial cells in vitro. Front Microbiol. 2016;7:1480. https://doi.org/10.3389/fmicb.2016.01480.

16. Fukuda S, Toh H, Taylor TD, Ohno H, Hattori M. Acetate-producing bifidobacteria protect the host from enteropathogenic infection via carbohydrate transporters. Gut Microbes. 2012;3(5):449-54. https://doi.org/1 0.4161 /gmic.21214.

17. Bohm S, Kruis W. Probiotics in chronic inflammatory bowel disease. MMW Fortschr Med. 2006;148(35-36):30-4.
18. Broekaert IJ, Walker WA. Probiotics and chronic disease. J Clin Gastroenterol. 2006;40(3):270-4. https://doi.org/10.1097/00004836-200603000-00021.

19. Yatsunenko T, Rey FE, Manary MJ, Trehan I, Dominguez-Bello MG, Contreras $M$, et al. Human gut microbiome viewed across age and geography. Nature. 2012;486(7402):222-7. https://doi.org/10.1038/nature11053.

20. Cheikhyoussef A, Pogori N, Chen W, Zhang H. Antimicrobial proteinaceous compounds obtained from bifidobacteria: from production to their application. Int J Food Microbiol. 2008;125(3):215-22. https://doi.org/10.101 6/j.ijfoodmicro.2008.03.012.

21. Luk B, Veeraragavan S, Engevik M, Balderas M, Major A, Runge J, et al. Postnatal colonization with human "infant-type" Bifidobacterium species alters behavior of adult gnotobiotic mice. PLoS One. 2018;13(5):e0196510. https://doi.org/10.1371/journal.pone.0196510.

22. Engevik MA, Luck B, Visuthranukul C, Ihekweazu FD, Engevik AC, Shi Z, et al. Human-derived Bifidobacterium dentium modulates the mammalian serotonergic system and gut-brain axis. Cell Mol Gastroenterol Hepatol. 2020;11(1):221-48. https://doi.org/10.1016/j.jcmgh.2020.08.002.

23. Luck B, Engevik MA, Ganesh BP, Lackey EP, Lin T, Balderas M, et al. Bifidobacteria shape host neural circuits during postnatal development by promoting synapse formation and microglial function. Sci Rep. 2020;10(1): 7737. https://doi.org/10.1038/s41598-020-64173-3.

24. Martens EC, Chiang HC, Gordon Jl. Mucosal glycan foraging enhances fitness and transmission of a saccharolytic human gut bacterial symbiont. Cell Host Microbe. 2008;4(5):447-57. https://doi.org/10.1016/j. chom.2008.09.007.

25. Ventura M, O'Flaherty S, Claesson MJ, Turroni F, Klaenhammer TR, van Sinderen D, et al. Genome-scale analyses of health-promoting bacteria: probiogenomics. Nat Rev Microbiol. 2009;7(1):61-71. https://doi.org/10.1038/ nrmicro2047.

26. Zoetendal EG, Raes J, van den Bogert B, Arumugam M, Booijink CC, Troost FJ, et al. The human small intestinal microbiota is driven by rapid uptake and conversion of simple carbohydrates. ISME J. 2012;6(7):1415-26. https:// doi.org/10.1038/ismej.2011.212.

27. Nicholson JK, Holmes E, Kinross J, Burcelin R, Gibson G, Jia W, et al. Host-gut microbiota metabolic interactions. Science. 2012;336(6086):1262-7. https:// doi.org/10.1126/science.1223813.

28. Lacroix C, de Wouters T, Chassard C. Integrated multi-scale strategies to investigate nutritional compounds and their effect on the gut microbiota. Curr Opin Biotechnol. 2015;32:149-55. https://doi.org/10.1016/j.copbio.2014.12.009.

29. Salonen A, de Vos WM. Impact of diet on human intestinal microbiota and health. Annu Rev Food Sci Technol. 2014;5(1):239-62. https://doi.org/10.114 6/annurev-food-030212-182554.

30. Turroni F, Bottacini F, Foroni E, Mulder I, Kim JH, Zomer A, et al. Genome analysis of Bifidobacterium bifidum PRL2010 reveals metabolic pathways for host-derived glycan foraging. Proc Natl Acad Sci U S A. 2010;107(45):195149. https://doi.org/10.1073/pnas.1011100107.

31. Lee JH, Karamychev VN, Kozyavkin SA, Mills D, Pavlov AR, Pavlova NV, et al. Comparative genomic analysis of the gut bacterium Bifidobacterium longum reveals loci susceptible to deletion during pure culture growth. BMC Genomics. 2008;9(1):247. https://doi.org/10.1186/1471-2164-9-247.

32. O'Connell Motherway M, Zomer A, Leahy SC, Reunanen J, Bottacini F, Claesson MJ, et al. Functional genome analysis of Bifidobacterium breve UCC2003 reveals type IVb tight adherence (Tad) pili as an essential and conserved host-colonization factor. Proc Natl Acad Sci U S A. 2011;108(27): 11217-22. https://doi.org/10.1073/pnas.1105380108.

33. Ventura M, Turroni F, Zomer A, Foroni E, Giubellini V, Bottacini F, et al. The Bifidobacterium dentium Bd1 genome sequence reflects its genetic adaptation to the human oral cavity. PLoS Genet. 2009:5(12):e1000785. https://doi.org/10.1371/journal.pgen.1000785.

34. Schell MA, Karmirantzou M, Snel B, Vilanova D, Berger B, Pessi G, et al. The genome sequence of Bifidobacterium longum reflects its adaptation to the human gastrointestinal tract. Proc Natl Acad Sci U S A. 2002;99(22):14422-7. https://doi.org/10.1073/pnas.212527599.

35. Barrangou R, Briczinski EP, Traeger LL, Loquasto JR, Richards M, Horvath $P$, et al. Comparison of the complete genome sequences of Bifidobacterium animalis subsp. lactis DSM 10140 and BI-04. J Bacteriol. 2009;191(13):414451. https://doi.org/10.1128/JB.00155-09.

36. Watson D, O'Connell Motherway M, Schoterman MH, van Neerven RJ, Nauta A, van Sinderen D. Selective carbohydrate utilization by lactobacilli and bifidobacteria. J Appl Microbiol. 2013;114(4):1132-46. https://doi.org/1 0.1111/jam.12105. 
37. Human Microbiome Project C. Structure, function and diversity of the healthy human microbiome. Nature. 2012;486(7402):207-14. https://doi. org/10.1038/nature11234.

38. Pokusaeva K, Johnson C, Luk B, Uribe G, Fu Y, Oezguen N, et al. GABA-producing Bifidobacterium dentium modulates visceral sensitivity in the intestine. Neurogastroenterol Motil. 2017;29(1). https://doi.org/10.1111/nmo.12904.

39. Nebra Y, Bonjoch X, Blanch AR. Use of Bifidobacterium dentium as an indicator of the origin of fecal water pollution. Appl Environ Microbiol. 2003; 69(5):2651-6. https://doi.org/10.1128/AEM.69.5.2651-2656.2003.

40. Menard O, Butel MJ, Gaboriau-Routhiau V, Waligora-Dupriet AJ. Gnotobiotic mouse immune response induced by Bifidobacterium sp. strains isolated from infants. Appl Environ Microbiol. 2008;74(3):660-6. https://doi.org/10.112 8/AEM.01261-07.

41. Ventura M, Elli M, Reniero R, Zink R. Molecular microbial analysis of Bifidobacterium isolates from different environments by the species-specific amplified ribosomal DNA restriction analysis (ARDRA). FEMS Microbiol Ecol. 2001;36(2-3):113-21. https://doi.org/10.1111/j.1574-6941.2001.tb00831.x.

42. Engevik MA, Luk B, Chang-Graham AL, Hall A, Herrmann B, Ruan W, et al. Bifidobacterium dentium fortifies the intestinal mucus layer via autophagy and calcium signaling pathways. mBio. 2019;10(3). https://doi.org/10.1128/ mBio.01087-19.

43. Hall AE, Engevik MA, Oezguen N, Haag A, Versalovic J. ClC transporter activity modulates histidine catabolism in Lactobacillus reuteri by altering intracellular pH and membrane potential. Microb Cell Factories. 2019;18(1): 212. https://doi.org/10.1186/s12934-019-1264-0.

44. Engevik MA, Morra CN, Roth D, Engevik K, Spinler JK, Devaraj S, et al. Microbial metabolic capacity for intestinal folate production and modulation of host folate receptors. Front Microbiol. 2019;10:2305. https:// doi.org/10.3389/fmicb.2019.02305.

45. Marchler-Bauer A, Bo Y, Han L, He J, Lanczycki CJ, Lu S, et al. CDD/SPARCLE: functional classification of proteins via subfamily domain architectures. Nucleic Acids Res. 2017:45(D1):D200-D3. https://doi.org/10.1093/nar/gkw1129.

46. Marchler-Bauer A, Derbyshire MK, Gonzales NR, Lu S, Chitsaz F, Geer LY, et al. CDD: NCBI's conserved domain database. Nucleic Acids Res. 2015; 43(Database issue):D222-6. https://doi.org/10.1093/nar/gku1221.

47. Marchler-Bauer A, Lu S, Anderson JB, Chitsaz F, Derbyshire MK, DeWeeseScott C, et al. CDD: a conserved domain database for the functional annotation of proteins. Nucleic Acids Res. 2011;39(Database issue):D225-9. https://doi.org/10.1093/nar/gkq1189.

48. Marchler-Bauer A, Bryant SH. CD-Search: protein domain annotations on the fly. Nucleic Acids Res. 2004;32(Web Server issue):W327-31. https://doi.org/1 0.1093/nar/gkh454

49. Maus JE, Ingham SC. Employment of stressful conditions during culture production to enhance subsequent cold- and acid-tolerance of bifidobacteria. J Appl Microbiol. 2003;95(1):146-54. https://doi.org/10.1046/j.1365-2672.2003.01954.x

50. Nakajo K, Takahashi N, Beighton D. Resistance to acidic environments of caries-associated bacteria: Bifidobacterium dentium and Bifidobacterium longum. Caries Res. 2010;44(5):431-7. https://doi.org/10.1159/000318582

51. Jiang Y, Ren F, Liu S, Zhao L, Guo H, Hou C. Enhanced acid tolerance in Bifidobacterium longum by adaptive evolution: comparison of the genes between the acid-resistant variant and wild-type strain. J Microbiol Biotechnol. 2016;26(3):452-60. https://doi.org/10.4014/jmb.1508.08030.

52. Sanchez B, Champomier-Verges MC, Collado Mdel C, Anglade P, Baraige F, Sanz Y, et al. Low-pH adaptation and the acid tolerance response of Bifidobacterium longum biotype longum. Appl Environ Microbiol. 2007; 73(20):6450-9. https://doi.org/10.1128/AEM.00886-07.

53. Matsumoto M, Ohishi H, Benno Y. H+-ATPase activity in Bifidobacterium with special reference to acid tolerance. Int J Food Microbiol. 2004;93(1): 109-13. https://doi.org/10.1016/j.ijfoodmicro.2003.10.009.

54. Kainulainen V, Reunanen J, Hiippala K, Guglielmetti S, Vesterlund S, Palva $A$, et al. BopA does not have a major role in the adhesion of Bifidobacterium bifidum to intestinal epithelial cells, extracellular matrix proteins, and mucus. Appl Environ Microbiol. 2013;79(22):6989-97. https://doi.org/10.1128/AEM.01993-13.

55. Lebeer S, Vanderleyden J, De Keersmaecker SC. Host interactions of probiotic bacterial surface molecules: comparison with commensals and pathogens. Nat Rev Microbiol. 2010;8(3):171-84. https://doi.org/10.1038/nrmicro2297.

56. Ewaschuk JB, Diaz H, Meddings L, Diederichs B, Dmytrash A, Backer J, et al Secreted bioactive factors from Bifidobacterium infantis enhance epithelial cell barrier function. Am J Physiol Gastrointest Liver Physiol. 2008;295(5): G1025-34. https://doi.org/10.1152/ajpgi.90227.2008.
57. Maynard CL, Elson CO, Hatton RD, Weaver CT. Reciprocal interactions of the intestinal microbiota and immune system. Nature. 2012;489(7415):231-41. https://doi.org/10.1038/nature11551.

58. Schwab C, Ruscheweyh HJ, Bunesova V, Pham VT, Beerenwinkel N, Lacroix C. Trophic interactions of infant Bifidobacteria and Eubacterium hallii during L-fucose and fucosyllactose degradation. Front Microbiol. 2017:8:95. https:// doi.org/10.3389/fmicb.2017.00095.

59. Svensson B. Protein engineering in the alpha-amylase family: catalytic mechanism, substrate specificity, and stability. Plant Mol Biol. 1994;25(2): 141-57. https://doi.org/10.1007/BF00023233.

60. Janecek S. Alpha-amylase family: molecular biology and evolution. Prog Biophys Mol Biol. 1997;67(1):67-97. https://doi.org/10.1016/s0079-6107(97)00015-1.

61. Davila AM, Blachier F, Gotteland M, Andriamihaja M, Benetti PH, Sanz Y, et al. Intestinal luminal nitrogen metabolism: role of the gut microbiota and consequences for the host. Pharmacol Res. 2013:68(1):95-107. https://doi. org/10.1016/j.phrs.2012.11.005.

62. Mikkelsen LL, Bendixen C, Jakobsen M, Jensen BB. Enumeration of bifidobacteria in gastrointestinal samples from piglets. Appl Environ Microbiol. 2003;69(1):654-8. https://doi.org/10.1128/aem.69.1.654-658.2003.

63. Rossi M, Corradini C, Amaretti A, Nicolini M, Pompei A, Zanoni S, et al. Fermentation of fructooligosaccharides and inulin by bifidobacteria: a comparative study of pure and fecal cultures. Appl Environ Microbiol. 2005; 71(10):6150-8. https://doi.org/10.1128/AEM.71.10.6150-6158.2005.

64. Bouhnik Y, Flourie B, Riottot M, Bisetti N, Gailing MF, Guibert A, et al. Effects of fructo-oligosaccharides ingestion on fecal bifidobacteria and selected metabolic indexes of colon carcinogenesis in healthy humans. Nutr Cancer. 1996;26(1):21-9. https://doi.org/10.1080/01635589609514459.

65. Bouhnik Y, Vahedi K, Achour L, Attar A, Salfati J, Pochart P, et al. Short-chain fructo-oligosaccharide administration dose-dependently increases fecal bifidobacteria in healthy humans. J Nutr. 1999;129(1):113-6. https://doi.org/1 0.1093/jn/129.1.113.

66. Gibson GR, Beatty ER, Wang X, Cummings JH. Selective stimulation of bifidobacteria in the human colon by oligofructose and inulin. Gastroenterology. 1995;108(4):975-82. https://doi.org/10.1016/00165085(95)90192-2.

67. Roller M, Clune Y, Collins K, Rechkemmer G, Watzl B. Consumption of prebiotic inulin enriched with oligofructose in combination with the probiotics Lactobacillus rhamnosus and Bifidobacterium lactis has minor effects on selected immune parameters in polypectomised and colon cancer patients. Br J Nutr. 2007;97(4):676-84. https://doi.org/10.1017/ S0007114507450292.

68. Ramirez-Farias C, Slezak K, Fuller Z, Duncan A, Holtrop G, Louis P. Effect of inulin on the human gut microbiota: stimulation of Bifidobacterium adolescentis and Faecalibacterium prausnitzii. Br J Nutr. 2009;101(4):541-50. https://doi.org/10.1017/S0007114508019880.

69. Fabich AJ, Jones SA, Chowdhury FZ, Cernosek A, Anderson A, Smalley D, et al. Comparison of carbon nutrition for pathogenic and commensal Escherichia coli strains in the mouse intestine. Infect Immun. 2008;76(3): 1143-52. https://doi.org/10.1128/IAl.01386-07.

70. Freter R. Factors affecting the microecology of the gut. In: Fuller R, editor. Probiotics: the scientific basis. Dordrecht: Springer Netherlands; 1992. p. 111-44. https://doi.org/10.1007/978-94-011-2364-8_6.

71. Stecher B, Hardt WD. Mechanisms controlling pathogen colonization of the gut. Curr Opin Microbiol. 2011;14(1):82-91. https://doi.org/10.1016/j.mib.201 0.10 .003 .

72. Becker MR, Paster BJ, Leys EJ, Moeschberger ML, Kenyon SG, Galvin JL, et al. Molecular analysis of bacterial species associated with childhood caries. J Clin Microbiol. 2002;40(3):1001-9. https://doi.org/10.1128/JCM.40.3.1001-1009.2002.

73. Eriksson L, Lif Holgerson P, Johansson I. Saliva and tooth biofilm bacterial microbiota in adolescents in a low caries community. Sci Rep. 2017;7(1): 5861. https://doi.org/10.1038/s41598-017-06221-z.

74. Crociani F, Biavati B, Alessandrini A, Chiarini C, Scardovi V. Bifidobacterium inopinatum sp. nov. and Bifidobacterium denticolens sp. nov., two new species isolated from human dental caries. Int J Syst Bacteriol. 1996;46(2): 564-71. https://doi.org/10.1099/00207713-46-2-564.

75. Modesto M, Biavati B, Mattarelli P. Occurrence of the family bifidobacteriaceae in human dental caries and plaque. Caries Res. 2006; 40(3):271-6. https://doi.org/10.1159/000092237.

76. Hojo K, Nagaoka S, Murata S, Taketomo N, Ohshima T, Maeda N. Reduction of vitamin $\mathrm{K}$ concentration by salivary Bifidobacterium strains and their possible nutritional competition with Porphyromonas gingivalis. J Appl 
Microbiol. 2007;103(5):1969-74. https://doi.org/10.1111/j.1365-2672.2007. 03436.x.

77. Edwardsson S. Bacteriological studies on deep areas of carious dentine. Odontol Revy Suppl. 1974;32:1-143.

78. Sanyal B, Russell C. Nonsporing, anaerobic, gram-positive rods in saliva and the gingival crevice of humans. Appl Environ Microbiol. 1978;35(4):670-8. https://doi.org/10.1128/AEM.35.4.670-678.1978.

79. Maeda N. Anaerobic, gram-positive, pleomorphic rods in human gingival crevice. Bull Tokyo Med Dent Univ. 1980;27(1):63-70.

80. Moore WE, Holdeman LV, Cato EP, Good IJ, Smith EP, Ranney RR, et al. Variation in periodontal floras. Infect Immun. 1984;46(3):720-6. https://doi. org/10.1128/IAl.46.3.720-726.1984

81. Mantzourani M, Gilbert SC, Sulong HN, Sheehy EC, Tank S, Fenlon M, et al. The isolation of bifidobacteria from occlusal carious lesions in children and adults. Caries Res. 2009;43(4):308-13. https://doi.org/10.1159/000222659.

82. Aas JA, Griffen AL, Dardis SR, Lee AM, Olsen I, Dewhirst FE, et al. Bacteria of dental caries in primary and permanent teeth in children and young adults. J Clin Microbiol. 2008;46(4):1407-17. https://doi.org/10.1128/JCM.01410-07.

83. Utto P, Teanpaisan R, Piwat S, Chandeying V. Assessment of prevalence, adhesion and surface charges of Bifidobacterium spp. isolated from Thai women with bacterial Vaginosis and healthy women. J Med Assoc Thail. 2017;100(1):1-8

84. Utto P, Piwat S, Teanpaisan R. Prevalence and adhesion properties of oral Bifidobacterium species in caries-active and caries-free Thai children. Walailak J. 2016;14(8):645-53.

85. Takahashi N, Xiao JZ, Miyaji K, Yaeshiima T, Hiramatsu A, Iwatsuki K, et al. Selection of acid tolerant bifidobacteria and evidence for a low-pHinducible acid tolerance response in Bifidobacterium longum. J Dairy Res. 2004;71(3):340-5. https://doi.org/10.1017/s0022029904000251.

86. Ventura M, Canchaya C, van Sinderen D, Fitzgerald GF, Zink R. Bifidobacterium lactis DSM 10140: identification of the atp (atpBEFHAGDC) operon and analysis of its genetic structure, characteristics, and phylogeny. Appl Environ Microbiol. 2004;70(5):3110-21. https://doi.org/10.1128/aem.70.5.3110-3121.2004.

87. Sanchez B, de los Reyes-Gavilan CG, Margolles A. The F1F0-ATPase of Bifidobacterium animalis is involved in bile tolerance. Environ Microbiol. 2006:8(10):1825-33. https://doi.org/10.1111/.j.1462-2920.2006.01067.x

88. Lugli GA, Tarracchini C, Alessandri G, Milani C, Mancabelli L, Turroni F, et al. Decoding the genomic variability among members of the Bifidobacterium dentium species. Microorganisms. 2020;8(11). https://doi.org/10.3390/ microorganisms 8111720 .

89. Maathuis AJ, van den Heuvel EG, Schoterman MH, Venema K. Galactooligosaccharides have prebiotic activity in a dynamic in vitro colon model using a (13) C-labeling technique. J Nutr. 2012;142(7):1205-12. https://doi. org/10.3945/jn.111.157420.

90. Menne E, Guggenbuhl N, Roberfroid M. Fn-type chicory inulin hydrolysate has a prebiotic effect in humans. J Nutr. 2000;130(5):1197-9. https://doi. org/10.1093/jn/130.5.1197.

91. Bosscher D, Van Loo J, Franck A. Inulin and oligofructose as prebiotics in the prevention of intestinal infections and diseases. Nutr Res Rev. 2006;19(2): 216-26. https://doi.org/10.1017/S0954422407249686.

92. Davis LM, Martinez I, Walter J, Hutkins R. A dose dependent impact of prebiotic galactooligosaccharides on the intestinal microbiota of healthy adults. Int J Food Microbiol. 2010;144(2):285-92. https://doi.org/10.1016/j. ijfoodmicro.2010.10.007.

93. Veereman-Wauters G, Staelens S, Van de Broek H, Plaskie K, Wesling F, Roger LC, et al. Physiological and bifidogenic effects of prebiotic supplements in infant formulae. J Pediatr Gastroenterol Nutr. 2011;52(6):763-71. https://doi. org/10.1097/MPG.0b013e3182139f39.

94. Ferrario C, Duranti S, Milani C, Mancabelli L, Lugli GA, Turroni F, et al. Exploring amino acid Auxotrophy in Bifidobacterium bifidum PRL2010. Front Microbiol. 2015;6:1331. https://doi.org/10.3389/fmicb.2015.01331.

95. Salyers AA, West SE, Vercellotti JR, Wilkins TD. Fermentation of mucins and plant polysaccharides by anaerobic bacteria from the human colon. Appl Environ Microbiol. 1977;34(5):529-33. https://doi.org/10.1128/AEM.34.5.529-533.1977.

96. Ruas-Madiedo P, Gueimonde M, Fernandez-Garcia M, de los Reyes-Gavilan CG, Margolles A. Mucin degradation by Bifidobacterium strains isolated from the human intestinal microbiota. Appl Environ Microbiol. 2008;74(6): 1936-40. https://doi.org/10.1128/AEM.02509-07.

97. Bayliss CE, Houston AP. Characterization of plant polysaccharide- and mucin-fermenting anaerobic bacteria from human feces. Appl Environ Microbiol. 1984;48(3):626-32. https://doi.org/10.1128/AEM.48.3.626-632.1984.
98. Abe F, Muto M, Yaeshima T, Iwatsuki K, Aihara H, Ohashi Y, et al. Safety evaluation of probiotic bifidobacteria by analysis of mucin degradation activity and translocation ability. Anaerobe. 2010;16(2):131-6. https://doi. org/10.1016/.janaerobe.2009.07.006.

99. Egan M, Motherway MO, Kilcoyne M, Kane M, Joshi L, Ventura M, et al. Cross-feeding by Bifidobacterium breve UCC2003 during co-cultivation with Bifidobacterium bifidum PRL2010 in a mucin-based medium. BMC Microbiol. 2014;14(1):282. https://doi.org/10.1186/s12866-014-0282-7.

100. Swiatecka D, Narbad A, Ridgway KP, Kostyra H. The study on the impact of glycated pea proteins on human intestinal bacteria. Int J Food Microbiol. 2011;145(1):267-72. https://doi.org/10.1016/j.jffoodmicro.2011.01.002.

101. Meddah AT, Yazourh A, Desmet I, Risbourg B, Verstraete W, Romond MB. The regulatory effects of whey retentate from bifidobacteria fermented milk on the microbiota of the simulator of the human intestinal microbial ecosystem (SHIME). J Appl Microbiol. 2001;91(6):1110-7. https://doi.org/10.1 046/j.1365-2672.2001.01482.x

102. Romond MB, Ais A, Guillemot F, Bounouader R, Cortot A, Romond C. Cellfree whey from milk fermented with Bifidobacterium breve C50 used to modify the colonic microflora of healthy subjects. J Dairy Sci. 1998:81(5): 1229-35. https://doi.org/10.3168/jds.S0022-0302(98)75683-8.

103. Singh RK, Chang HW, Yan D, Lee KM, Ucmak D, Wong K, et al. Influence of diet on the gut microbiome and implications for human health. J Transl Med. 2017;15(1):73. https://doi.org/10.1186/s12967-017-1175-y.

104. Eid N, Enani S, Walton G, Corona G, Costabile A, Gibson G, et al. The impact of date palm fruits and their component polyphenols, on gut microbial ecology, bacterial metabolites and colon cancer cell proliferation. J Nutr Sci. 2014;3:e46. https://doi.org/10.1017/jns.2014.16.

105. Parvin S, Easmin D, Sheikh A, Biswas M, SCD S, MGS J, et al. Nutritional analysis of date fruits (Phoenix dactylifera L.) in perspective of Bangladesh. Am J Life Sci. 2015;3(4):274-8. https://doi.org/10.11648/.j.ajs.20150304.14.

106. Costabile A, Klinder A, Fava F, Napolitano A, Fogliano V, Leonard C, et al. Whole-grain wheat breakfast cereal has a prebiotic effect on the human gut microbiota: a double-blind, placebo-controlled, crossover study. Br J Nutr. 2008:99(1):110-20. https://doi.org/10.1017/S0007114507793923.

107. Carvalho-Wells AL, Helmolz K, Nodet C, Molzer C, Leonard C, McKevith B, et al. Determination of the in vivo prebiotic potential of a maize-based whole grain breakfast cereal: a human feeding study. Br J Nutr. 2010;104(9): 1353-6. https://doi.org/10.1017/50007114510002084.

108. Wu GD, Chen J, Hoffmann C, Bittinger K, Chen YY, Keilbaugh SA, et al. Linking long-term dietary patterns with gut microbial enterotypes. Science. 2011;334(6052):105-8. https://doi.org/10.1126/science.1208344.

109. Reddy BS, Weisburger JH, Wynder EL. Effects of high risk and low risk diets for colon carcinogenesis on fecal microflora and steroids in man. J Nutr. 1975;105(7):878-84. https://doi.org/10.1093/jn/105.7.878.

110. Drasar BS, Crowther JS, Goddard P, Hawksworth G, Hill MJ, Peach S, et al. The relation between diet and the gut microflora in man. Proc Nutr Soc. 1973;32(2):49-52. https://doi.org/10.1079/pns19730014.

111. McFarland LV. Meta-analysis of probiotics for the prevention of traveler's diarrhea. Travel Med Infect Dis. 2007;5(2):97-105. https://doi.org/10.1016/j. tmaid.2005.10.003.

112. Pandey KR, Naik SR, Vakil BV. Probiotics, prebiotics and synbiotics- a review. J Food Sci Technol. 2015;52(12):7577-87. https://doi.org/10.1007/s13197-01 5-1921-1.

113. Fukuda S, Toh H, Hase K, Oshima K, Nakanishi Y, Yoshimura K, et al. Bifidobacteria can protect from enteropathogenic infection through production of acetate. Nature. 2011;469(7331):543-7. https://doi.org/10.103 8/nature09646.

114. Pinto-Sanchez Ml, Hall GB, Ghajar K, Nardelli A, Bolino C, Lau JT, et al. Probiotic Bifidobacterium longum NCC3001 reduces depression scores and alters brain activity: a pilot study in patients with irritable bowel syndrome. Gastroenterology. 2017;153(2):448-59 e8. https://doi.org/10.1053/j.gastro.201 7.05.003.

115. Bercik P, Park AJ, Sinclair D, Khoshdel A, Lu J, Huang X, et al. The anxiolytic effect of Bifidobacterium longum NCC3001 involves vagal pathways for gutbrain communication. Neurogastroenterol Motil. 2011;23(12):1132-9. https:// doi.org/10.1111/j.1365-2982.2011.01796.x.

116. Messaoudi M, Lalonde R, Violle N, Javelot H, Desor D, Nejdi A, et al. Assessment of psychotropic-like properties of a probiotic formulation (Lactobacillus helveticus R0052 and Bifidobacterium longum R0175) in rats and human subjects. Br J Nutr. 2011;105(5):755-64. https://doi.org/10.1017/ S0007114510004319 
117. Desbonnet L, Garrett L, Clarke G, Kiely B, Cryan JF, Dinan TG. Effects of the probiotic Bifidobacterium infantis in the maternal separation model of depression. Neuroscience. 2010;170(4):1179-88. https://doi.org/10.1016/j. neuroscience.2010.08.005.

118. Saavedra JM, Bauman NA, Oung I, Perman JA, Yolken RH. Feeding of Bifidobacterium bifidum and Streptococcus thermophilus to infants in hospital for prevention of diarrhoea and shedding of rotavirus. Lancet. 1994; 344(8929):1046-9. https://doi.org/10.1016/S0140-6736(94)91708-6.

119. Bernet MF, Brassart D, Neeser JR, Servin AL. Adhesion of human bifidobacterial strains to cultured human intestinal epithelial cells and inhibition of enteropathogen-cell interactions. Appl Environ Microbiol. 1993; 59(12):4121-8. https://doi.org/10.1128/AEM.59.12.4121-4128.1993.

120. Sekine K, Toida T, Saito M, Kuboyama M, Kawashima T, Hashimoto Y. A new morphologically characterized cell wall preparation (whole peptidoglycan) from Bifidobacterium infantis with a higher efficacy on the regression of an established tumor in mice. Cancer Res. 1985;45(3):1300-7.

121. Rowland IR, Rumney CJ, Coutts JT, Lievense LC. Effect of Bifidobacterium longum and inulin on gut bacterial metabolism and carcinogen-induced aberrant crypt foci in rats. Carcinogenesis. 1998;19(2):281-5. https://doi.org/1 0.1093/carcin/19.2.281.

122. Le Leu RK, Hu Y, Brown IL, Woodman RJ, Young GP. Synbiotic intervention of Bifidobacterium lactis and resistant starch protects against colorectal cancer development in rats. Carcinogenesis. 2010;31(2):246-51. https://doi. org/10.1093/carcin/bgp197.

123. Tavan E, Cayuela C, Antoine JM, Cassand P. Antimutagenic activities of various lactic acid bacteria against food mutagens: heterocyclic amines. J Dairy Res. 2002;69(2):335-41. https://doi.org/10.1017/S002202990200540X.

124. Pool-Zobel BL, Neudecker C, Domizlaff I, Ji S, Schillinger U, Rumney C, et al. Lactobacillus- and bifidobacterium-mediated antigenotoxicity in the colon of rats. Nutr Cancer. 1996;26(3):365-80. https://doi.org/10.1080/0163 5589609514492.

125. Chenoll E, Rivero M, Codoner FM, Martinez-Blanch JF, Ramon D, Genoves S, et al. Complete genome sequence of Bifidobacterium longum subsp. infantis Strain CECT 7210, a probiotic strain active against rotavirus infections. Genome Announc. 2015;3(2). https://doi.org/10.1128/genomeA.00105-15.

126. Patole SK, Rao SC, Keil AD, Nathan EA, Doherty DA, Simmer KN. Benefits of Bifidobacterium breve M-16V supplementation in preterm neonates - a retrospective cohort study. PLoS One. 2016;11(3):e0150775. https://doi.org/1 0.1371/journal.pone.0150775.

127. Venturi A, Gionchetti P, Rizzello F, Johansson R, Zucconi E, Brigidi P, et al. Impact on the composition of the faecal flora by a new probiotic preparation: preliminary data on maintenance treatment of patients with ulcerative colitis. Aliment Pharmacol Ther. 1999;13(8):1103-8. https://doi. org/10.1046/j.1365-2036.1999.00560.x.

128. Gionchetti P, Rizzello F, Venturi A, Campieri M. Probiotics in infective diarrhoea and inflammatory bowel diseases. J Gastroenterol Hepatol. 2000; 15(5):489-93. https://doi.org/10.1046/j.1440-1746.2000.02162.x.

129. Marteau P, Cuillerier E, Meance S, Gerhardt MF, Myara A, Bouvier M, et al. Bifidobacterium animalis strain DN-173 010 shortens the colonic transit time in healthy women: a double-blind, randomized, controlled study. Aliment Pharmacol Ther. 2002;16(3):587-93. https://doi.org/10.104 6/j.1365-2036.2002.01188.x

130. Andrade S, Borges N. Effect of fermented milk containing Lactobacillus acidophilus and Bifidobacterium longum on plasma lipids of women with normal or moderately elevated cholesterol. J Dairy Res. 2009;76(4):469-74. https://doi.org/10.1017/S0022029909990173.

131. Guyonnet D, Chassany O, Ducrotte P, Picard C, Mouret M, Mercier CH, et al. Effect of a fermented milk containing Bifidobacterium animalis DN-173 010 on the health-related quality of life and symptoms in irritable bowel syndrome in adults in primary care: a multicentre, randomized, doubleblind, controlled trial. Aliment Pharmacol Ther. 2007;26(3):475-86. https:// doi.org/10.1111/j.1365-2036.2007.03362.x.

132. Yang $Y X$, He $M, H u G$, Wei J, Pages $P$, Yang $X H$, et al. Effect of a fermented milk containing Bifidobacterium lactis DN-173010 on Chinese constipated women. World J Gastroenterol. 2008;14(40):6237-43. https://doi.org/10.3748/ wjg.14.6237.

133. Kleessen B, Sykura B, Zunft HJ, Blaut M. Effects of inulin and lactose on fecal microflora, microbial activity, and bowel habit in elderly constipated persons. Am J Clin Nutr. 1997;65(5):1397-402. https://doi.org/10.1093/ajcn/ 65.5.1397.
134. Duffy LC, Zielezny MA, Riepenhoff-Talty M, Dryja D, Sayahtaheri-Altaie S, Griffiths $\mathrm{E}$, et al. Reduction of virus shedding by B. bifidum in experimentally induced MRV infection. Statistical application for ELISA. Dig Dis Sci. 1994; 39(11):2334-40. https://doi.org/10.1007/BF02087647.

135. Duffy LC, Zielezny MA, Riepenhoff-Talty M, Dryja D, Sayahtaheri-Altaie S, Griffiths $E$, et al. Effectiveness of Bifidobacterium bifidum in experimentally induced MRV infection: dietary implications in formulas for newborns. Endocr Regul. 1993;27(4):223-9.

136. Perdigon G, Alvarez S, Rachid M, Aguero G, Gobbato N. Immune system stimulation by probiotics. J Dairy Sci. 1995;78(7):1597-606. https://doi.org/1 0.3168/jds.S0022-0302(95)76784-4.

137. Picard C, Fioramonti J, Francois A, Robinson T, Neant F, Matuchansky C. Review article: bifidobacteria as probiotic agents -- physiological effects and clinical benefits. Aliment Pharmacol Ther. 2005;22(6):495-512. https://doi. org/10.1111/j.1365-2036.2005.02615.x.

138. Gueimonde M, Margolles A, de los Reyes-Gavilan CG, Salminen S. Competitive exclusion of enteropathogens from human intestinal mucus by Bifidobacterium strains with acquired resistance to bile--a preliminary study. Int J Food Microbiol. 2007;113(2):228-32. https://doi.org/10.1016/j. ijfoodmicro.2006.05.017.

139. Schroeder BO, Birchenough GMH, Stahlman M, Arike L, Johansson MEV, Hansson GC, et al. Bifidobacteria or fiber protects against diet-induced microbiota-mediated colonic mucus deterioration. Cell Host Microbe. 2018; 23(1):27-40 e7. https://doi.org/10.1016/j.chom.2017.11.004.

140. Gomi A, Harima-Mizusawa N, Shibahara-Sone H, Kano M, Miyazaki K, Ishikawa F. Effect of Bifidobacterium bifidum BF-1 on gastric protection and mucin production in an acute gastric injury rat model. J Dairy Sci. 2013; 96(2):832-7. https://doi.org/10.3168/jds.2012-5950.

141. Javed NH, Alsahly MB, Khubchandani J. Oral feeding of probiotic Bifidobacterium infantis: colonic morphological changes in rat model of TNBS-induced colitis. Scientifica (Cairo). 2016;2016:9572596. https://doi.org/1 $0.1155 / 2016 / 9572596$.

142. Kawahara T, Makizaki Y, Oikawa Y, Tanaka Y, Maeda A, Shimakawa M, et al. Oral administration of Bifidobacterium bifidum G9-1 alleviates rotavirus gastroenteritis through regulation of intestinal homeostasis by inducing mucosal protective factors. PLoS One. 2017;12(3):e0173979. https://doi.org/1 0.1371/journal.pone.0173979.

143. Khailova L, Dvorak K, Arganbright KM, Halpern MD, Kinouchi T, Yajima M, et al. Bifidobacterium bifidum improves intestinal integrity in a rat model of necrotizing enterocolitis. Am J Physiol Gastrointest Liver Physiol. 2009;297(5): G940-9. https://doi.org/10.1152/ajpgi.00141.2009.

\section{Publisher's Note}

Springer Nature remains neutral with regard to jurisdictional claims in published maps and institutional affiliations.

Ready to submit your research? Choose BMC and benefit from:

- fast, convenient online submission

- thorough peer review by experienced researchers in your field

- rapid publication on acceptance

- support for research data, including large and complex data types

- gold Open Access which fosters wider collaboration and increased citations

- maximum visibility for your research: over $100 \mathrm{M}$ website views per year

At $\mathrm{BMC}$, research is always in progress.

Learn more biomedcentral.com/submissions 